\title{
informationpower
}

\section{Recommendations about publishing and publication procurement practices across the health and social care system}

\section{November 2020}

\section{Contents}

Introduction

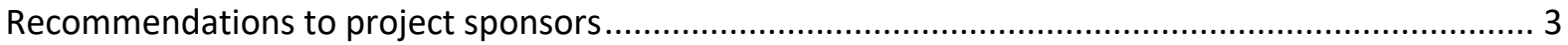

(1) Develop a shared OA strategy and common policies and principles ....................................... 3

(2) Invest in financial, publication, and compliance tracking........................................................ 3

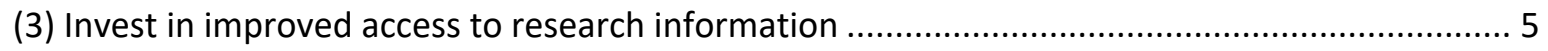

(4) Centralise and strengthen your negotiations with publishers, ideally in partnership with UK universities.

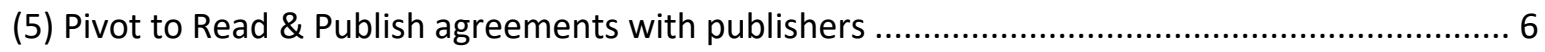

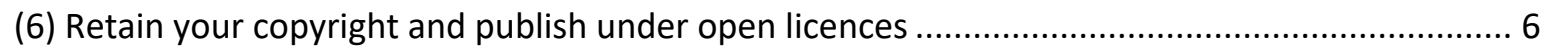

(7) Immediate green OA for articles not published gold OA ...................................................... 7

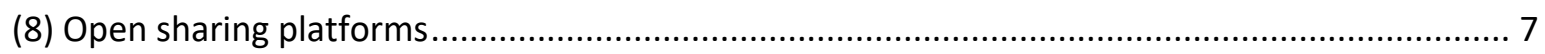

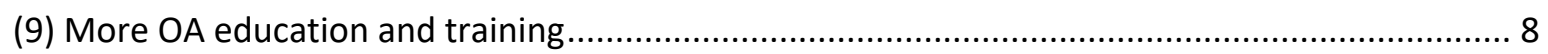

(10) Require overviews of research in plain English, and provide training and support to enable

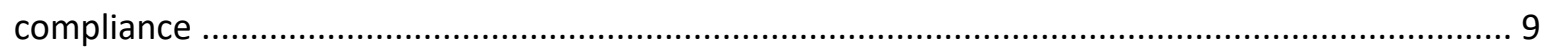

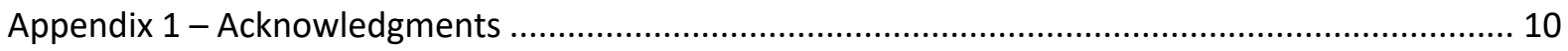

Appendix 2 - Publishing practices across the health and social care system ................................... 12

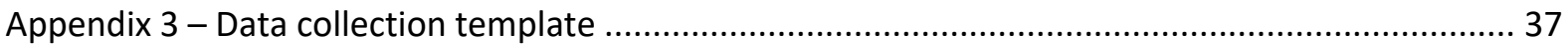

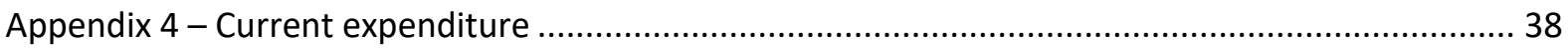

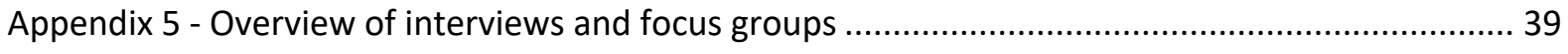

Appendix 6 - Open Access Publishing and the health and social care system: summary of a strategic roundtable..... 


\section{Introduction}

This study was commissioned by the Department of Health and Social Care and Health Education England to inform development of Open Access (OA) strategy and policy in the UK health and social care system. OA ensures that research publications, such as journal articles or books, are freely available online to everyone for access to read and re-use. There are new opportunities to embrace $\mathrm{OA}$ approaches that have already been developed, tested, and proven effective for medical research funders, by Plan $\mathrm{S}^{1}$ for example, and for employers, by members of Universities $\mathrm{UK}^{2}$ for example.

The NHS in England is undertaking more research than ever before. However, investment on access to research outputs, through library subscriptions, is relatively low. The available data (see Appendix 4) suggests that Arm's Length Bodies collectively spend under $f 1 \mathrm{~m}$ per annum on primary journals and a similar amount per annum on journals in aggregated databases. NHS Trusts collectively spend an estimated $£ 4 \mathrm{~m}$ per annum on journal subscriptions. Taken together, the combined NHS expenditure is less than a single medium-sized UK university which seems starkly out of alignment with the importance of evidence-based care decisions.

In addition, NIHR spends a significant amount to publish articles that report on its funded research. We estimate that this figure is in excess of $f 10 \mathrm{~m}$ per annuum, however the precise figure is unknown because costs are included in grants awarded through a range of programmes, and open access expenditure is not explicitly tracked at present. We analysed 121,915 papers (see Appendix 2) published between 2015 -2019 by authors employed in, or funded through, the UK health and social care system. 85,542 or $70 \%$ of the papers were published Open Access (OA) which means they are freely available for anyone in the world to read. $34 \%$ of the total articles are immediately available (19\% of all papers were published as fully Gold OA, and $15 \%$ as hybrid Gold OA) and $36 \%$ of the total articles are available after a delay period of six months (19\% were published and made available as Green OA, and $17 \%$ as Bronze OA).

\begin{tabular}{|l|l|}
\hline Publishing costs have been paid upfront & $\begin{array}{l}\text { Near-final draft has been shared publicly, after } \\
\text { a delay of six months }\end{array}$ \\
\hline $\begin{array}{l}\text { Gold - costs typically paid by author from } \\
\text { research grants }\end{array}$ & $\begin{array}{l}\text { Green - a version of the article (either the } \\
\text { manuscript as originally submitted or as } \\
\text { accepted, or the final published version) is } \\
\text { shared via an institutional repository or subject } \\
\text { repository }\end{array}$ \\
\hline $\begin{array}{l}\text { Platinum - costs typically paid by employer, } \\
\text { funder, or another sponsor often with a per- } \\
\text { article charge }\end{array}$ & $\begin{array}{l}\text { Bronze - a version of the article is shared via } \\
\text { the publisher's site }\end{array}$ \\
\hline $\begin{array}{l}\text { Diamond - costs typically paid by employer, } \\
\text { funder, or another sponsor without any per- } \\
\text { article charge }\end{array}$ & \\
\hline
\end{tabular}

\footnotetext{
${ }^{1}$ https://www.coalition-s.org/

${ }^{2}$ https://www.universitiesuk.ac.uk/policy-and-analysis/research-policy/open-science/Pages/uuk-open-accesscoordination-group.aspx
} 
This represents good compliance with the NIHR OA mandate, and there is scope for further improvement. Papers with a co-author affiliated with a higher education university are more likely to be available OA ( $80 \%$ vs. $65 \%$ ). There is some degree of overlap, of course, as some papers include authors from both sectors. This suggests that looking to good practice in the UK university sector offers insight about good ways forward.

Our qualitative research (see Appendix 5) suggests that there is support for the principles of Open Access by researchers, research managers, and library and information professionals in the health and social care system. Funding for APCs is the primary barrier to researchers publishing their articles $\mathrm{OA}$, however researchers affiliated to, or collaborating with someone affiliated to, universities have less difficulty making their research outputs available OA. Central funding, for example block grants, would drive beneficial change as would centralised and strengthened engagement with publishers, and more education and training. Finally, OA is essential but not enough in itself as there is a clear need for short, actionable summaries of research outputs to inform clinical practice.

The following recommendations focus on opportunities to increase value for money to the taxpayer by eliminating elements of double payment in this system (for subscriptions and OA publication), by raising standards through better access to research information, and by ensuring publicly funded research information is opened for wider economic and social gain.

\section{Recommendations to project sponsors}

\section{(1) Develop a shared OA strategy and common policies and principles}

A shared OA strategy across the health and social care system is needed to advance the quality and speed of research, and to enable equitable access to knowledge. By working together across the DHSC, NIHR, and Arm's Length Bodies it will be possible to best leverage the sector's scale, align and change practice, avoid duplication of effort, and obtain best value for money. The NIHR Open Access policy and the Concordat for Maximising Digital Knowledge are good vehicles for this, and the recommendations in this report can form the basis of a shared approach.

Common policy and high-level principles would enable organisations to focus on collaborative action to drive immediate open access for health and social care system research outputs. NIHR's direction of travel (i.e. immediate open access with no embargos, no barriers to re-use and dissemination, publications freely discoverable, and reasonable costs covered) resonates with stakeholders with whom we engaged.

A coordination group across the DHSC, NIHR, and Arm's Length Bodies is needed to align goals and behaviour, to promote mutual understanding, to cut through complexities and obstacles, and to cultivate buy-in and consensus over time.

\section{(2) Invest in financial, publication, and compliance tracking}

In order to monitor the impact of your strategy and policies, more attention is needed to build a database that will enable you to understand how information is created, accessed, paid for, and 
used in the health and social care system. More attention to data gathering can also help you to set policies, negotiate with publishers, and make the case to DHSC for funding.

Appendix 2 contains our detailed quantitative analysis of your publishing patterns. We recommend that you establish reliable methods for monitoring research publications going forward:

- invest in databases such as Dimensions, Scopus, or Web of Science, and/or by implementing CRIS systems so your researchers or librarians can track research outputs. There are costs in terms of both time and money to each approach.

- ask Dimensions to set up GRID codes for the remaining organisations, to facilitate future tracking; this can be done relatively simply and at no cost.

- ensure RORs ${ }^{3}$ are created for each organisation in the health and social care system and consider working with database providers such as Dimensions, Scopus, and Web of Science (and other similar service providers) to give them the identifiers they would need to improve their matching algorithms.

- ensure researchers in the health and social care system have ORCID researcher identification numbers ${ }^{4}$.

- improve data in ResearchFish by encouraging researchers to supply the DOI of the final published version of articles and to ensure correct employer and funder affiliation data is included in their articles.

- review what instructions are given to these researchers regarding the correct acknowledgment of employer and funder/s in papers, making sure that the text is specific about how NIHR and the Arm's Length Bodies should be cited.

- seek information from other funders for insight into best practice in encouraging grant recipients to include correct employer and funder acknowledgments in papers.

- track all expenditure made with any publisher, both for subscriptions and for OA. The negotiation of more cost-effective agreements with publishers also requires reliable data about the amounts paid for APCs and of all articles written by affiliated researchers.

To maximize compliance with your open access policies, incentives and sanctions will be needed. Enabling only papers immediately available open access to be entered for hiring and promotion decisions would be a powerful incentive. Ineligibility for further NIHR funding would be a powerful sanction.

Ensure that all Arm's Length Bodies and NHS Trusts are accountable for ensuring the research of their staff members is available open access immediately upon publication. Interviews with researchers suggested that they receive little or no organisational support to make their outputs open access unless they are in the privileged position of having a joint appointment to a higher education institution.

Rather than have OA funding follow the grant and be administered by individual researchers, we recommend you consider ways of channelling OA funding via these employers, for example by using block grants. While there is a different sort of bureaucracy involved with these, by transmitting money to organisations in this way you would create an environment with increased accountability which will drive up compliance with your policies.

\footnotetext{
${ }^{3}$ https://ror.org/

${ }^{4}$ https://orcid.org/
} 


\section{(3) Invest in improved access to research information}

We recommend you explore ways to increase investment to ensure that researchers and clinicians can both access to the best scientific information from around the world and publish their research articles open access. The public contributor workshops carried out by NIHR as part of their OA policy review identified that even if patients and the public do not access primary research themselves, they expect that clinicians and care practitioners do and are making decisions based on the best scientific information.

The NHS in England is undertaking more research than ever before. However, investment on access to research outputs, through library subscriptions, is relatively low. The available data suggests that Arm's Length Bodies collectively spend under $£ 1 \mathrm{~m}$ per annum on primary journals and a similar amount per annum on journals in aggregated databases. NHS Trusts collectively spend an estimated $\mathrm{f} 4 \mathrm{~m}$ per annum on journal subscriptions. Taken together, the combined NHS expenditure is less than a single medium-sized UK university which seems starkly out of alignment with the importance of evidence-based care decisions. More insight about the expenditure data we were able to collect is reported in Appendix 4.

Based on pilots already done ${ }^{5}$, we estimate that providing subscription access to the scope of scientific journals available in UK universities would cost an additional of $£ 1-2 \mathrm{~m} /$ year. This investment could be targeted in various ways, but one approach to consider is targeting on the journals in which researchers linked to DHSC Arm's Length Bodies and NHS Trusts publish, but to which there is no access. We also encourage continued migration to central discovery platforms and services.

NIHR spends a significant but unknown amount per annum on APCs for journal articles. In 2019, 27,416 articles were published by researchers linked to DHSC Arm's Length Bodies and NHS Trusts. While the good news is that $70 \%$ are $\mathrm{OA}, 30 \%$ remain behind publishers' paywalls. Providing financial support to ensure all research outputs are published gold OA could therefore cost an additional of f17.7m [unfunded articles $8256 x$ average APC $f 2147=f 17,725,632$ ]. This is clearly a significant additional expenditure, but by implementing the other recommendations in this paper it is possible to significantly reduce this figure.

\section{(4) Centralise and strengthen your negotiations with publishers, ideally in partnership with UK universities}

Currently the journal content available via HEE is acquired through public sector procurement processes. Whilst this helps ensure best value in markets where there is a choice of supplier, it not ideal in a market where publisher's journal content is unique and cannot be obtained via other providers. Neither are public sector procurement process designed for the detailed discussion and negotiations needed to develop innovative OA journal agreements which cover both accesses to journal content, and publication in those same journals. We encourage you to centralise and strengthen your engagement with publishers.

We recommend that you implement a system-wide policy to avoid any form of Non-Disclosure Agreement with publishers. We were rather concerned that one of the Arm's Length Bodies had

5

https://community.jisc.ac.uk/system/files/515/NHS\%20\%28Finch\%29\%20Pilot\%20outcomes\%20Nov\%202016 \%20and\%20Cochrane\%20website\%20sharing.pdf

5|An independent report by Information Power ip 
done so and were therefore unable to share their expenditure information with any other Arm's Length Body.

We recommend you explore a collaborative partnership with Jisc Collections so that your negotiating strength and power is coupled with those of UK universities. This leverage is your best option to control costs and secure better publishing agreements from a range of relevant publishers but particularly the largest. Between them Elsevier, Springer Nature, and Wiley publish 54\% of NIHRfunded papers.

Jisc is expert in negotiating cost-effective journal agreements, but does not have deep sectoral knowledge. We therefore recommend the creation of a strong steering group chaired by HEE to guide them. A potential investment could be the appointment or secondment of a member of staff at Jisc to strengthen their understanding of the health sector and medical publishers.

Where there are publishers who are important for the health and social care system, but not the HEI part of it, then consider strengthening your own negotiations by partnering with the Royal Colleges and strengthening the knowledge and skills of the NICE negotiating team.

\section{(5) Pivot to Read \& Publish agreements with publishers}

In order to maximise value for the public purse, we recommend you bring together your subscription spend with publishers with your expenditure for OA publishing and seek agreements with publishers that support both reading and publishing. This means that affiliated authors can publish OA without paying an APC. PHE has already done some experimentation in securing such agreements with publishers.

We recommend that you seek OA agreements with small and medium sized publishers as well as large publishers. There is quality content produced by Society and other publishers, and it is essential for cost constraint that there is good competition between publishers for authors.

In advance of any negotiations, we recommend that any publisher with whom you have an agreement is required to complete and return the data collection template at Appendix $\mathbf{3}$ and Annex A.

In the absence of such agreements, we recommend that you do not provide funding for OA publications in a publisher's hybrid titles. This is because your existing subscription expenditure will give you full access to the content in these titles, and additional APC payments do not lead to a transition to full OA, merely boost publisher profits and surplus.

\section{(6) Retain your copyright and publish under open licences}

A very powerful way to increase your negotiation power with publishers is to encourage or require employees in the health and social care system to retain necessary copyrights. This is already a requirement for Crown Servants. We recommend that as a condition of NIHR funding, or employment with an Arm's Length Body, researchers should be required to retain sufficient intellectual property rights to comply with their funder and employer OA requirements.

Attention also needs to be paid to education around, and compliance tracking of, the open licences attached to $O A$ articles published by researchers in the health and social care system. We strongly recommend use of Creative Commons (CC-BY) and Open Government (OGL) licences across the 
health and social care system, especially as rights need to be retained in order to enable immediate green $\mathrm{OA}$ (see next recommendation).

DHSC, its Arm's Length Bodies, and NHS Trusts all publish reports and other materials on their websites. The copyright status of these publications is often unclear, and we would encourage you to use a CC-BY or OGL license wherever possible on these publications.

\section{(7) Immediate green OA for articles not published gold OA}

As the proportion of articles published OA in the health and social care system grows, you need to ensure that any articles published under the subscription model also become immediately available. Including green OA options - specifically the immediate self-archiving of peer reviewed accepted manuscripts in one health-oriented repository such as Europe PMC - should be an essential part of your strategy. Including this requirement in your agreement with publishers will enable you to maximise OA outputs while constraining costs.

Understandably publishers have been unwilling to agree to immediate green $\mathrm{OA}$, and there is too often little incentive for them to do so. The immediate availability of accepted manuscripts under a CC-BY licence is perceived by publishers as likely to undermine the value of their subscription sales in all other parts of the world. Every new article published OA and brought out in front of their paywall not only erodes the value of subscription sales to other parts of the world, but can also fuel rival online services underpinned by so-called black OA (i.e. content piracy) ${ }^{6}$.

The debate around whether there is risk to publishers of short embargo green OA is as heated as it is long standing. We take a pragmatic view: only the test of time will prove whether or not there is a real risk to subscription revenue from short embargo green $O A$, however publisher perceptions of risk mean few are willing to incorporate short embargo green $O A$ into their transformative (and other $\mathrm{OA}$ ) agreements. It is in their interest to control costs and therefore pragmatic for the health and social care system to find a way forward.

Publishers incur new costs to provide new OA services (e.g. adding author and funder metadata, informing authors about terms of agreements, encouraging authors to share articles providing new reports and metadata, etc). Where publishers expect an uplift in price in exchange for uncapped article numbers in a transformative agreement because the level of publishing output is high, and are willing to provide these new OA services, then we recommend modest financial incentives in otherwise cost-neutral agreements to incentivise the inclusion of immediate green OA. This would help the health and social care system secure more affordable transformative agreements and enable researchers to retain a wide choice in where they publish while delivering both full OA and maximising value for money.

\section{(8) Open sharing platforms}

Shared infrastructure is required to support the cost-effective dissemination of open outputs by your researchers. A collective approach should be part of your strategy to ensure access to research

\footnotetext{
${ }^{6}$ Gold, green, and black open access by Bo-Christer Björk https://onlinelibrary.wiley.com/doi/full/10.1002/leap.1096
} 
outputs is not fragmented across different organisations and services, and to avoid duplication of costs.

In developing the common strategy for this infrastructure is important not to reinvent wheels but to explore the utilisation of existing open platforms. NIHR is one of the funders of Europe PubMed Central which is an open-access repository containing millions of biomedical research papers and has potential to serve as a shared repository service for all your affiliated authors.

Longer term, you may want to consider not only a repository for access to research, but an open shared platform for publishing NHS health and care research. The AMRC (Association of Medical Research Charities) and Wellcome Trust both maintain open research platforms on which all their funded researchers can publish OA any results they think are worth sharing at an extremely low price. Publication is fast, there is transparent peer review and editorial guidance on making all source data openly available. AMRC Open Research publishes other research outputs, for example posters, slides, and documents, reporting any basic scientific, translational, applied, and clinical research studies: we heard at the round table that these types of research output are as important to the health and care sector as scholarly research. Both the AMRC and Wellcome Trust open platforms use technology provided by F1000 Research Limited.

A shared open platform such as F1000 research could be helpful in decreasing the costs of OA publishing. The list price of publishing a research article on such a platform is only $\$ 1350$ per article as opposed to nearly $\$ 3000$ per article in journals.

\section{(9) More OA education and training}

Our interviews revealed widespread support for the principles of open access, but fragmented understanding of all the flavours of open access and constraints to supporting its delivery in practice. The specific requirements vary by stakeholder group and include:

- Libraries - open access models, how to support researchers to publish open access, how to work with publishers to maximise open access outputs and constrain costs for access to research, supporting researchers to share via Europe PMC

- Researchers - open access models, how to obtain funding to support open access publishing, how to identify and avoid predatory journals, how to correctly use unique identifiers for funders/grants/employers/co-authors

- Research managers - why a research culture is important to the health and social care section, how to define the impact of research undertaken, why it is important that research outputs are available to all, what open access is, open access models, how to ensure research is immediately available open access

We recommend you develop education and training materials and courses that can be used across the health and social care system to minimise confusion and to provide consistent information and guidance. 


\section{(10) Require overviews of research in plain English, and provide training and support to enable compliance}

Your shared strategy and common policies and principles must consider 'actionable knowledge', as well as open access. Research findings must inform practitioner decisions and practice. Plain English summaries of research outputs will aid busy practitioners who do not have time to read research articles, as well as patients and members of the public

There are already some examples of good practice in the sector:

- the NIHR Centre for Engagement and Dissemination is producing accessible and audiencetargeted evidence resources and sharing them across a broad stakeholder community

- The NIHR provides guidance to researchers on how to write plain English summaries ${ }^{7}$.

- There are also commercially available services and tools which could assist in this effort. For example, Kudos, which is a free to researchers, allows them to describe their work in plain English, and to enrich their descriptions by adding related resources like blog posts and videos. Scholarcy is a charged-for service which uses Artificial Intelligence to create a summary flashcards of research articles.

${ }^{7}$ https://www.nihr.ac.uk/documents/plain-english-summaries/27363 


\section{Appendix 1 - Acknowledgments}

Many people generously contributed their time through interviews and participation in focus groups.

\section{Interviews}

Paul Ayris, Pro-Vice-Provost (UCL Library Services), University College London

Rajinder Flora, National Institute for Health Research

Hannah Hope, Wellcome Trust

Rachel Illingworth, NHS Nottingham and Nottinghamshire CCG

Dr Matt Lee, NIHR Clinical Lecturer - General Surgery, Department of Oncology and Metabolism, University of Sheffield

Ric Paul, Health Services Library, Southampton General Hospital \& University of Southampton

Professor David Price, Vice-Provost (Research), University College London

David Pye, Local Government Association

Deb Wall, Leicester City Clinical Commissioning Group

Astrid Wissenburg, Director of Research, University of Exeter

Edwin van Leeuwen, Mathematical Modeller, Public Health England

\section{Focus groups}

\section{Group 1: Researcher and Research Managers}

Angela Cree, University of Southampton Faculty of Medicine

Helen Pidd, Director, UK Clinical Research Facility network and Operational Director, Research \& Innovation, Manchester University NHS Foundation Trust

Brian Littlechild, Professor in School of Health and Social Work, University of Hertfordshire

Donna Richardson, Asst Director NIHR Applied Research Collaboration East Midlands

Matt Stevenson, Professor of Health Technology Assessment (a health economist) at the University of Sheffield School of Health and Related Research

Richard Trowbridge, Research Manager, University of Southampton School of Health Sciences via ARC

\section{Group 2: Researcher and Research Managers}

Judy Henwood, Head of Research Design and Evaluation, NHS Norfolk and Waveney CCG

Mark Howells, Head of research and evidence, Nottinghamshire Healthcare NHS Foundation Trust Sandra Igbodo, NW Ambulance Service Trust

Vivienne Shaw, Head of Research \& Development at NHS Cambridgeshire and Peterborough Clinical Commissioning Group

Katie Warner, Head of R\&D, Berkshire Healthcare NHS Trust

\section{Group 3: Library and information professionals}

YiWen Hon,_Royal Marsden Trust

Susan Smith, Mid Cheshire Hospitals NHS Foundation Trust

Steve Glover, Mid Cheshire Hospitals NHS Foundation Trust

Marion Spring, NICE

Matt Holland, NHS Ambulance Service in England

Jane Gray, NHS Blood \& Transplant

Emily Hopkins, HEE

Isla Kuhn, University of Cambridge which supplies services to Trust

Owen Coxall, University of Oxford which supplies services to Trust

Georgina Wildman, Imperial Medical Library which supplies services to Trust

\section{Roundtable}


Yomi Adegbaju, NHS Blood and Transplant Beth Allen, Department of Health \& Social Care Dr Alison Austin, NHS England/Improvement Sara Ball, UK Research and Innovation Helen Bingham, Health Education England Rachel Bruce, UK Research and Innovation Sue Lacey Bryant, Health Education England Helene Gorring, Health Education England Dr Felix Greaves, National Institute for Health and Care Excellence Professor Bernie Hannigan, Public Health England Rachel Illingworth, NHS R\&D Forum Evidence for Commissioning Group Candace Imison, NIHR Centre for Engagement and Dissemination

Dr Nick McNally, University College London Hospitals NHS Foundation Trust and UK Research \& Development

Patrick Mitchell, Health Education England

Alice Murray, National Institute for Health and Care Excellence

Barbara Murray, Chief Social Worker's Office

Ashleigh Peel Lowes, NHS Business Services Authority

Scott Rosenberg, Public Health England

Paul Rudd, Public Health England

Lisa Smith, Research in Practice

Keith Spink, Social Care Institute for Excellence

Dr Inesa Thomsen, Department of Health \& Social Care

Juliet Whitworth, Local Government Association

Colin Winter, NHS Business Services Authority

Dr Louise Wood, Department of Health \& Social Care

Naho Yamazaki, Health Research Authority 


\section{Appendix 2 - Publishing practices across the health and social care system}

For this project we used Dimensions (www.dimensions.ai), a database produced by Digital Science listing publications, grants, datasets, patents and policy documents. It lists over 106 million publications. It focusses on research publications and outputs, and so does not contain data on more news-orientated publications such as Nursing Times.

We searched the Dimensions database for papers with authors (corresponding authors or otherwise) affiliated with the following organisations:

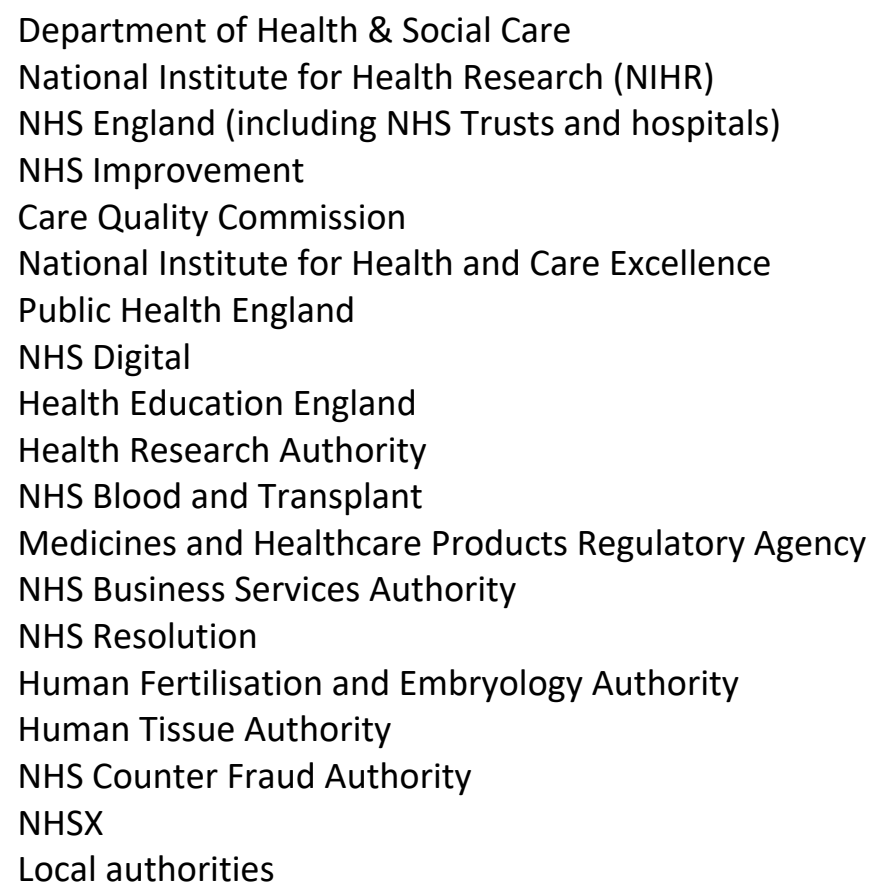

Employers outside the health and social care system were clustered as follows:

English universities

Other UK universities

Overseas universities

Industry

Charities and other non-profit organisations

The primary data search used Dimensions' GRID codes to determine author affiliations. These codes are global unique identifiers for Research Organisations, allowing them to be reliably disambiguated, and the database is freely available under a Creative Commons Licence. Not all organisations have been assigned GRID codes. The following do have GRIDs:

Department of Health \& Social Care National Institute for Health Research (NIHR)

NHS England (including NHS Trusts and hospitals)

National Institute for Health and Care Excellence

Public Health England 
NHS Digital

NHS Blood and Transplant

Human Fertilisation and Embryology Authority

NHSX

We recommend that Dimensions be asked to set up GRID codes for the remaining organisations, to facilitate future tracking; this can be done relatively simply and at no cost. In the longer term, we suggest that you ensure $\mathrm{RORs}^{8}$ are created for each organisation in the health and social care system and consider working with database providers such as Dimensions, Scopus, and Web of Science to give them the identifiers they would need to improve their matching algorithms.

Although NIHR do not employ researchers directly, authors often cite NIHR as an affiliation in publications, and so it was essential to include this in the affiliation search.

We topped up these records with an additional full-text search for author details which bought the total to 99,586 records, and an additional full-text search for NIHR which produced an additional 6519 records. $2.5 \%$ of the records contained no publisher data; this was reduced to $0.3 \%$ by adding data manually.

To produce year-on-year trend comparisons with complete years, we dropped from the pool papers published in 2020, leaving a total of 88,425 publication records.

No publications were found for the NHS Counter Fraud Authority. Only a few were found for NHSX, and these were all 2020 publications - the organisation was formed too recently for any research conducted to show up in 2019 publications. Neither organisation is considered further here.

Local Authorities present a particular problem. Firstly, there is no straightforward way of searching for authors from LAs; they do not have GRID codes, and there are no common features likely to be included in affiliation text that would facilitate a search. Secondly, there is no simple way to distinguish healthcare papers from, say, papers on municipal engineering or economics. An informal manual search looking for several local authorities by name produced very few results, and none that seemed to be healthcare related. If further data on LAs is required, we recommend that further work be commissioned directly with the database suppliers to undertake further research to develop a way to identify any publications. Our expectation, however, is that there may not be a great deal to find; formal publication of rigorously conducted research does not have the same career imperatives for LA staff as it does for researchers in other settings. This is something we have explored further during interviews and focus groups.

A second data search focussed on NIHR-acknowledged papers, rather than looking at authorship. NIHR provided a list of papers from ResearchFish comprising publications reported by NIHR-funded authors. After filtering for date and type of publication and deduping internally by DOI, this yielded 32,961 records for papers published in 2015-19.These records were matched with the corresponding Dimensions records and combined with a Dimension search of papers for which NIHR was acknowledged in the funding section, giving a total of 53,957 records.

20,996 (39\%) of these papers had NIHR acknowledged in the paper, picked up by Dimensions, but were not recorded in the ResearchFish list. Although to some extent this may partly be a reporting compliance problem, there were confounding issues with the ResearchFish list:

\footnotetext{
${ }^{8}$ https://ror.org/
} 
- Most notably, NIHR Centre for Business Intelligence reported that the list included only the most recent submission for each award. Grants funding multiple papers could result in significant numbers of missing papers.

- Awards made jointly with the NIHR Efficacy and Mechanism Evaluation (EME) programme and the Medical Research Council were not included.

- Responses from SPCR had been excluded from the data supplied to us.

Conversely, the ResearchFish list contained 35,419 unique records within scope, of which Dimensions were able to match 32,961 (93\%). The remainder could be unmatched for several reasons:

- The ResearchFish DOI may refer to a green OA version, while Dimensions records the final published version. We recommend that authors be encouraged to supply the DOI of the final published version of record.

- Some publications in the ResearchFish list provided no usable identifiers (DOI, PMID, or PMCID). Again, we recommend that these be recorded by authors wherever possible.

- Some ResearchFish data was inaccurate; for example, some publication dates were incorrect, and some publication types incorrectly recorded.

- Dimensions reported that in some cases there was a mismatch in DOI strings, e.g. capitalisation differences. It is disappointing that Dimensions are not able to deal with the latter, but again, authors need to ensure that all aspects of the data they submit, including capitalisation, are correct.

- Analysis by NIHR of the ResearchFish data identified that researchers often log publications and research findings on Researchfish that build on the findings from NIHR funded research, but where funding now comes from another source. Further, the NIHR found that in a review of research outputs from the NIHR Fellowships, funded researchers were often logging all of their research publications whilst receiving an NIHR fellowship, even if the research in question was not funded by NIHR. These factors could explain the lack of NIHR funding acknowledgement.

In summary, for this data pool Dimensions identified significantly more NIHR acknowledged papers than the ResearchFish list, for the reasons outlined. They were unable to match 2458 records, which comprise a maximum of $4.3 \%$ of the total data pool and probably less, depending on the reasons in each case.

Putting the two data pools together and removing duplicates leaves a total of 121,915 papers (journal articles plus preprints) published between 2015 and 2019 with either authors from the health and social care system, NIHR funding, an NIHR association, or a combination of the three. In the following analysis we make it clear which dataset (based on authors, funding, or the two combined) is under examination.

Going forward, to improve the ResearchFish data we recommend that researchers in the health and social care system be asked to ensure correct employer and funder affiliation data is added to their articles by the corresponding author. It might also be helpful to review what instructions are given to these researchers regarding the correct acknowledgment of institution and funder in papers, making sure that the text is specific about how NIHR and the Arm's Length Bodies should be cited.

1. How many articles are published by researchers in the health and social care system?

Looking at the combined dataset, a total of 121,915 papers were published over the five years 20152019, with a clear increasing trend (Table 1.1) 


\begin{tabular}{|l|l|}
\hline 2015 & 22192 \\
\hline 2016 & 23388 \\
\hline 2017 & 23691 \\
\hline 2018 & 25228 \\
\hline 2019 & 27416 \\
\hline Total & 121915 \\
\hline
\end{tabular}

Table 1.1 Total papers by year

Within the health and social care system, $65 \%$ of these papers had a co-author from NHS England, and 3.5\% had a co-author affiliated to Public Health England. No other Arm's-Length Body contributed more than $0.4 \%$. There is of course overlap. For example, $5.5 \%$ of NHS in England papers included a PHE co-author.

$62 \%$ of papers included a co-author from an English University, $6.5 \%$ one from a Scottish, Welsh or Northern Irish University, and $30 \%$ a co-author from an overseas university. $7 \%$ of papers included a co-author from a non-profit, and $4.5 \%$ one from industry.

The increasing trend across time is clear for each of these organisations (Table 1.2)

\begin{tabular}{|c|c|c|c|c|c|c|}
\hline & 2015 & 2016 & 2017 & 2018 & 2019 & Total \\
\hline NHS England & 13953 & 14687 & 15201 & 16246 & 18704 & 78791 \\
\hline Public Health England & 789 & 843 & 851 & 848 & 964 & 4295 \\
\hline NHS Blood and Transplant & 86 & 79 & 103 & 123 & 133 & 524 \\
\hline NICE & 60 & 73 & 76 & 84 & 75 & 368 \\
\hline Department of Health \& Social Care ${ }^{9}$ & 61 & 77 & 49 & 82 & 90 & 359 \\
\hline Health Education England & 19 & 39 & 82 & 84 & 109 & 333 \\
\hline MHRA & 60 & 68 & 56 & 64 & 69 & 317 \\
\hline NHS Improvement & 0 & 4 & 18 & 19 & 30 & 71 \\
\hline NHS Digital & 17 & 10 & 9 & 8 & 7 & 51 \\
\hline Care Quality Commission & 15 & 12 & 8 & 5 & 11 & 51 \\
\hline Health Research Authority & 1 & 4 & 7 & 3 & 7 & 22 \\
\hline NHS Resolution & 0 & 0 & 2 & 2 & 1 & 5 \\
\hline HFEA & 0 & 0 & 1 & 2 & 1 & 4 \\
\hline NHS Business Services Authority & 0 & 0 & 0 & 2 & 1 & 3 \\
\hline Human Tissue Authority & 1 & 0 & 1 & 0 & 0 & 2 \\
\hline English universities & 12697 & 13850 & 14514 & 16362 & 17972 & 75395 \\
\hline Other UK universities & 1208 & 1482 & 1613 & 1727 & 1929 & 7959 \\
\hline Overseas universities & 5679 & 6468 & 7146 & 8285 & 9441 & 37019 \\
\hline $\begin{array}{l}\text { Charities and other non-profit } \\
\text { organisations }\end{array}$ & 1300 & 1537 & 1708 & 1914 & 2121 & 8580 \\
\hline Industry & 816 & 997 & 1062 & 1283 & 1337 & 5495 \\
\hline
\end{tabular}

\footnotetext{
${ }^{9} \mathrm{NB}$ : We believe that these papers are likely to be NIHR funded rather than DHSC funded, but researchers have acknowledged the incorrect funding source. Going forward, it will be important to ask researchers to provide accurate employer and funder information for their papers and to provide them with detailed guidance on how to do so.
} 
Table 1.2. Total papers by year and organisation

\section{Which funders are acknowledged in these articles?}

$45 \%$ of the papers acknowledged at least one funder. $12 \%$ listed just one, $13 \%$ listed two, and $20 \%$ listed three or more. $1 \%$ listed more than ten funders.

A total of 1314 separate funders were listed. The top 25 are listed in Table 2.1.

\begin{tabular}{|l|r|}
\hline Funder & No. mentions \\
\hline National Institute for Health Research & 21936 \\
\hline Medical Research Council & 14391 \\
\hline Wellcome Trust & 7893 \\
\hline British Heart Foundation & 4989 \\
\hline Cancer Research UK & 4036 \\
\hline European Commission & 3539 \\
\hline Department of Health and Social Care & 2316 \\
\hline Biotechnology and Biological Sciences Research Council & 1906 \\
\hline Engineering and Physical Sciences Research Council & 1784 \\
\hline Economic and Social Research Council & 1518 \\
\hline European Research Council & 1274 \\
\hline National Cancer Institute & 1253 \\
\hline NIHR Evaluation Trials and Studies Coordinating Centre & 1127 \\
\hline South London and Maudsley NHS Foundation Trust & 1039 \\
\hline Canadian Institutes of Health Research & 1036 \\
\hline Versus Arthritis & 956 \\
\hline National Heart Lung and Blood Institute & 947 \\
\hline Guy's and St Thomas' NHS Foundation Trust & 844 \\
\hline NIHR Trainees Coordinating Centre & 819 \\
\hline National Health and Medical Research Council & 766 \\
\hline National Institute of Allergy and Infectious Diseases & 712 \\
\hline GlaxoSmithKline (United Kingdom) & 683 \\
\hline National Institute of Diabetes and Digestive and Kidney Diseases & 679 \\
\hline National Institute on Aging & 659 \\
\hline Scottish Government Health and Social Care Directorates & 646 \\
\hline
\end{tabular}

Table 2.1 Top 25 funders

Dimensions groups funders into broad categories, and we have used these to summarise the data by author affiliation (Table 2.2)

A sample of the papers with no funding data in Dimensions was examined. Going back to the original publications, most indeed made no mention of funding. Several stated positively that there was no funding (some journals follow best practice and require a funding statement whether there is any or not), and several were of the nature of case reports etc. where funding would not be expected. One paper was found (in a sample of 15) where Dimensions had missed a funding statement. It is therefore possible that Dimensions understates the funders slightly. It is also possible, where no 
funding statement is compulsory, that some authors fail to provide this information, but there is no way to determine the extent to which this might be the case.

Of the 32,961 papers reported to NIHR through ResearchFish only $75 \%$ had NIHR acknowledged as a funder in Dimensions. $17 \%$ of the papers recorded other funders but not NIHR, and $8 \%$ recorded no funding at all. This could be down to the issue raised earlier, or it could be that where NIHR-funded authors are not the corresponding authors, they may not be passing on that information so that it is recorded accurately in the paper or in publishers' submission system. We recommend NIHR ask other funders for insight into best practice in encouraging correct employer and funder acknowledgment in papers by grant recipients. 


\begin{tabular}{|c|c|c|c|c|c|c|c|c|c|c|c|c|c|c|c|}
\hline & \multicolumn{15}{|c|}{ Funders } \\
\hline & AMRC & CDC & cOAlition S & DoD & EU (EC \& ERC) & HRA & ICRP $^{10}$ & NAPHRO & NIH & NSF & US DoE & UKRI & USDA & NASA & NIHR \\
\hline NHS in England & 9845 & 91 & 12973 & 126 & 2429 & 460 & 14657 & 59 & 2797 & 55 & 37 & 9996 & 5 & 2 & 14973 \\
\hline PHE & 542 & 48 & 1266 & 10 & 293 & 4 & 1181 & 6 & 189 & 9 & 24 & 799 & 0 & 1 & 980 \\
\hline NHS B\&T & 99 & 0 & 104 & 1 & 28 & 1 & 130 & 0 & 22 & 0 & 0 & 90 & 0 & 0 & 169 \\
\hline NICE & 16 & 1 & 38 & 0 & 13 & 1 & 36 & 0 & 1 & 1 & 0 & 22 & 0 & 0 & 68 \\
\hline DHSC & 29 & 0 & 67 & 0 & 19 & 1 & 76 & 0 & 12 & 0 & 0 & 51 & 0 & 0 & 64 \\
\hline MHRA & 26 & 3 & 78 & 0 & 30 & 2 & 73 & 0 & 24 & 3 & 0 & 49 & 0 & 0 & 44 \\
\hline HEE & 4 & 0 & 6 & 0 & 1 & 0 & 26 & 0 & 0 & 0 & 0 & 3 & 0 & 0 & 17 \\
\hline NHS D & 1 & 0 & 6 & 0 & 2 & 0 & 3 & 0 & 0 & 1 & 1 & 5 & 0 & 0 & 9 \\
\hline CQC & 4 & 0 & 3 & 0 & 0 & 0 & 7 & 0 & 2 & 0 & 0 & 3 & 0 & 0 & 8 \\
\hline NHS I & 1 & 0 & 1 & 0 & 0 & 0 & 1 & 0 & 1 & 0 & 0 & 0 & 0 & 0 & 6 \\
\hline HRA & 3 & 0 & 9 & 0 & 1 & 0 & 8 & 0 & 0 & 0 & 0 & 7 & 0 & 0 & 6 \\
\hline HTA & 0 & 0 & 1 & 0 & 0 & 0 & 1 & 0 & 0 & 0 & 0 & 1 & 0 & 0 & 0 \\
\hline HFEA & 0 & 0 & 2 & 0 & 0 & 0 & 1 & 0 & 0 & 0 & 0 & 2 & 0 & 0 & 0 \\
\hline NHS BSA & 1 & 0 & 0 & 0 & 0 & 0 & 1 & 0 & 0 & 0 & 0 & 0 & 0 & 0 & 0 \\
\hline NHS R & 0 & 0 & 0 & 0 & 0 & 0 & 0 & 0 & 0 & 0 & 0 & 0 & 0 & 0 & 0 \\
\hline English unis & 19586 & 123 & 27046 & 201 & 5162 & 559 & 21888 & 103 & 42630 & 109 & 26 & 21888 & 17 & 8 & 41235 \\
\hline Other UK unis & 2591 & 20 & 3777 & 20 & 671 & 95 & 3343 & 20 & 4750 & 17 & 4 & 3343 & 0 & 0 & 4497 \\
\hline $0 / S$ unis & 8850 & 147 & 13227 & 232 & 3851 & 572 & 9798 & 124 & 19168 & 155 & 48 & 9798 & 23 & 13 & 17304 \\
\hline Non-profit & 2972 & 75 & 3906 & 100 & 1355 & 227 & 2724 & 33 & 4835 & 36 & 18 & 2724 & 5 & 0 & 4184 \\
\hline Industry & 1272 & 12 & 1797 & 17 & 583 & 79 & 1404 & 10 & 2354 & 10 & 5 & 1404 & 1 & 2 & 2091 \\
\hline
\end{tabular}

Table 2.2. Funders acknowledged in papers, by author affiliation. 17\% of NIHR acknowledged papers had no authors with English HEI affiliations, and $16 \%$ had no authors with UK HEI affiliations.

\footnotetext{
${ }^{10}$ International Cancer Research Partnership
}

18I An independent report by Information Power ip 
3. What proportion of the articles acknowledge: NIHR only, NIHR and one or more additional funders, or research funded by organisations other than NIHR?

Where the numbers are high enough to determine a trend (and where a funder has been acknowledged), about $20-30 \%$ of authors in the health and social care system only acknowledge NIHR as a funder. In general, the proportions of papers with NIHR and other funders acknowledged are higher (18-45\%), and papers with other funders but no NIHR acknowledgment account for the remainder (33-54\%) (Table 3.1).

\begin{tabular}{|c|c|c|c|c|c|c|c|}
\hline & \multicolumn{2}{|l|}{ NIHR only } & \multicolumn{2}{|c|}{ NIHR plus other funders } & \multicolumn{2}{|c|}{ Only other funders } & \multirow[t]{2}{*}{ Total } \\
\hline & No. & $\%$ & No. & $\%$ & No. & $\%$ & \\
\hline NHS England & 6449 & $24 \%$ & 8524 & $32 \%$ & 11650 & $44 \%$ & 26623 \\
\hline PHE & 420 & $20 \%$ & 560 & $26 \%$ & 1138 & $54 \%$ & 2118 \\
\hline NHS B\&T & 79 & $30 \%$ & 90 & $35 \%$ & 91 & $35 \%$ & 260 \\
\hline NICE & 45 & $35 \%$ & 23 & $18 \%$ & 59 & $46 \%$ & 127 \\
\hline DHSC & 26 & $20 \%$ & 38 & $29 \%$ & 65 & $50 \%$ & 129 \\
\hline MHRA & 17 & $12 \%$ & 27 & $19 \%$ & 100 & $69 \%$ & 144 \\
\hline HEE & 11 & $26 \%$ & 6 & $14 \%$ & 26 & $60 \%$ & 43 \\
\hline NHS Digital & 7 & $44 \%$ & 2 & $13 \%$ & 7 & $44 \%$ & 16 \\
\hline CQC & 6 & $43 \%$ & 2 & $14 \%$ & 6 & $43 \%$ & 14 \\
\hline NHS Improvement & 5 & $56 \%$ & 1 & $11 \%$ & 3 & $33 \%$ & 9 \\
\hline HRA & 1 & $9 \%$ & 5 & $45 \%$ & 5 & $45 \%$ & 11 \\
\hline $\begin{array}{l}\text { Human Tissue } \\
\text { Authority }\end{array}$ & 1 & $100 \%$ & 0 & $0 \%$ & 0 & $0 \%$ & 1 \\
\hline HFEA & 0 & $0 \%$ & 1 & $33 \%$ & 2 & $67 \%$ & 3 \\
\hline NHS BSA & 0 & $0 \%$ & 1 & $33 \%$ & 2 & $67 \%$ & 3 \\
\hline NHS Resolution & 0 & $0 \%$ & 1 & $100 \%$ & 0 & $0 \%$ & 1 \\
\hline Total & 9834 & & 15038 & & 17323 & & \\
\hline
\end{tabular}

Table 3.1. Proportions of papers acknowledging NIHR or other funding. (Percentages are the proportion of papers with authors from that organisation where funding has been reported).

Looking at the NIHR acknowledged or Researchfish reported articles where no authors from Arm's Length Bodies are listed, between $62 \%$ and $76 \%$ of papers have additional funding sources acknowledged apart from NIHR (Table 3.2).

\begin{tabular}{|l|l|r|r|r|r|}
\hline & \multicolumn{2}{l|}{ NIHR only } & \multicolumn{2}{l|}{ NIHR plus other funders } & \multicolumn{2}{l|}{ Total } \\
\hline & \multicolumn{2}{|l|}{ No. } & \multicolumn{2}{l|}{ No. } & \multicolumn{2}{l|}{} \\
\hline English universities & 10416 & $38 \%$ & 16918 & $62 \%$ & 27334 \\
\hline Other UK universities & 934 & $32 \%$ & 1998 & $68 \%$ & 2932 \\
\hline O/S universities & 3893 & $32 \%$ & 8440 & $68 \%$ & 12333 \\
\hline Non-profit & 343 & $27 \%$ & 930 & $73 \%$ & 1273 \\
\hline Industry & 601 & $24 \%$ & 1895 & $76 \%$ & 2496 \\
\hline
\end{tabular}

Table 3.2. Proportions of papers reporting additional funding where there are no authors from Arm's Length Bodies. (Percentages are the proportion of papers with authors from that organisation type).

19|Recommendations about publishing and publication procurement practices across the health and social care system. An independent report by Information Power. 
4. Which journals these articles are published in, and which publishers are responsible for these journals?

By author

Firstly, we examined the papers published by authors employed within the health and social care sector. Over the five-year period, papers were published in approximately 5,300 journals. The top 50 journals are listed in Table 4.1.

\begin{tabular}{|l|l|}
\hline Journal & 5-year total \\
\hline BMJ Open & 1278 \\
\hline BMJ Case Reports & 1120 \\
\hline PLoS ONE & 995 \\
\hline Journal of Clinical Oncology & 949 \\
\hline Rheumatology & 913 \\
\hline Archives of Disease in Childhood & 905 \\
\hline Blood & 852 \\
\hline The BMJ & 798 \\
\hline International Journal of Surgery & 783 \\
\hline Gut & 780 \\
\hline European Journal of Surgical Oncology & 777 \\
\hline Annals of Oncology & 729 \\
\hline Cochrane Database of Systematic Reviews & 706 \\
\hline The Lancet & 607 \\
\hline Thorax & 604 \\
\hline Scientific Reports & 580 \\
\hline Annals of The Royal College of Surgeons of England & 537 \\
\hline Annals of the Rheumatic Diseases & 480 \\
\hline Sexually Transmitted Infections & 454 \\
\hline Journal of Neurology Neurosurgery \& Psychiatry & 444 \\
\hline Heart & 440 \\
\hline Trials & 427 \\
\hline British Journal of Oral and Maxillofacial Surgery & 405 \\
\hline British Journal of Hospital Medicine & 401 \\
\hline Clinical Medicine & 376 \\
\hline Anaesthesia & 373 \\
\hline European Heart Journal & 370 \\
\hline British Journal of Haematology & 341 \\
\hline Journal of the American College of Cardiology & 334 \\
\hline Emergency Medicine Journal & 332 \\
\hline Nature Communications & 309 \\
\hline Physiotherapy & 296 \\
\hline Eye & 283 \\
\hline European Respiratory Journal & 282 \\
\hline
\end{tabular}

20|Recommendations about publishing and publication 


\begin{tabular}{|l|l|}
\hline Future Healthcare Journal & 282 \\
\hline The Bone \& Joint Journal & 282 \\
\hline Age and Ageing & 280 \\
\hline European Journal of Vascular and Endovascular Surgery & 256 \\
\hline Hepato Pancreato Biliary & 248 \\
\hline British Journal of Dermatology & 246 \\
\hline British Journal of General Practice & 242 \\
\hline Journal of Antimicrobial Chemotherapy & 239 \\
\hline Value in Health & 236 \\
\hline BMJ Supportive \& Palliative Care & 235 \\
\hline Nephrology, Dialysis and Transplantation & 234 \\
\hline BMJ Simulation and Technology Enhanced Learning & 232 \\
\hline Clinical Radiology & 231 \\
\hline British Journal of Cancer & 228 \\
\hline Journal of Hospital Infection & 225 \\
\hline Comparative Haematology International & 222 \\
\hline
\end{tabular}

Table 4.1. Top journals (authors from Arm's Length Bodies)

However, there is not much consistency from year to year, even among the bigger journals (Fig 4.1).

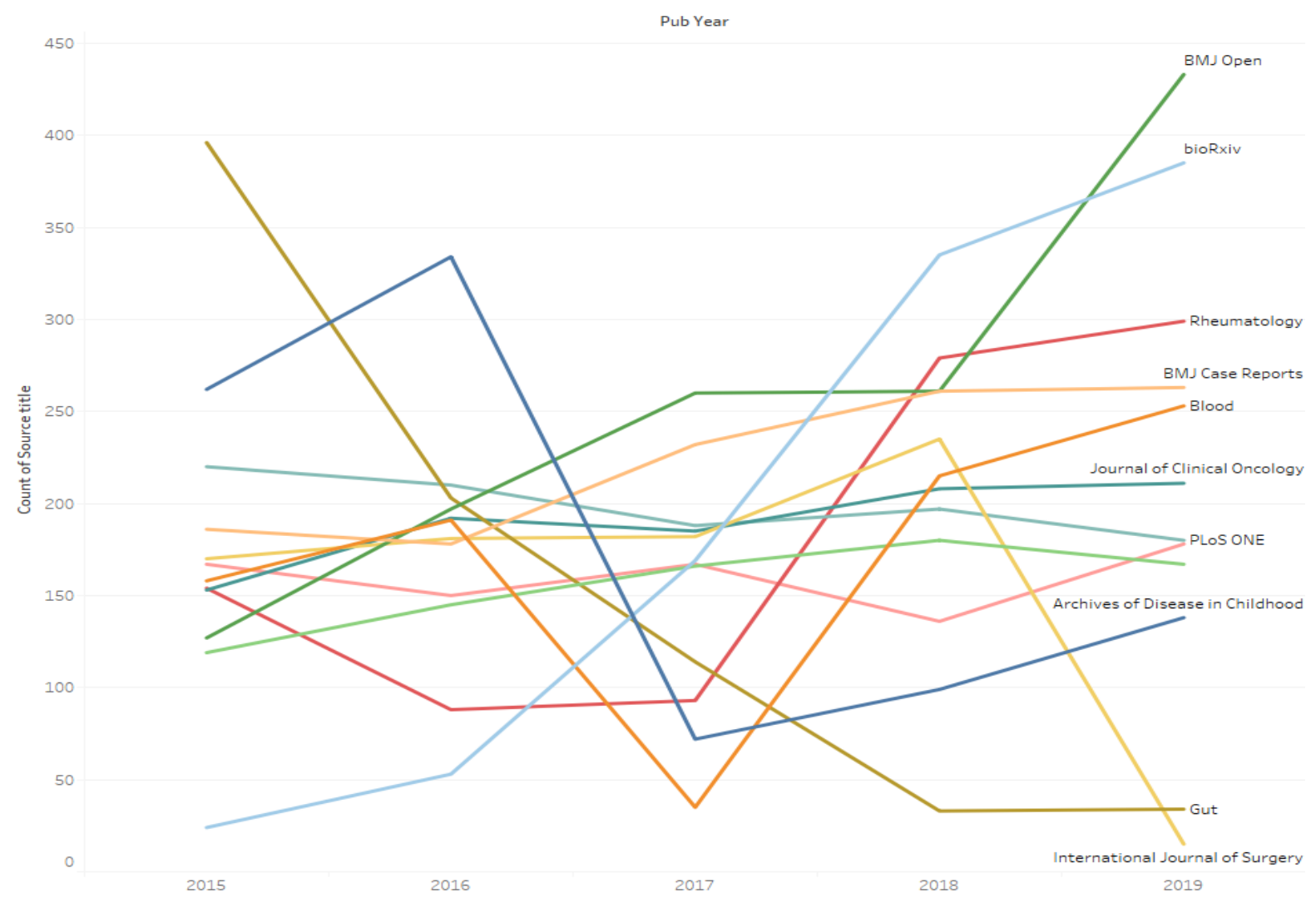

Fig 4.1. Top journals by year

21 Recommendations about publishing and publication 
These 5,300 journals are published by 460 different publishers. The top 50 publishers are shown in Table 4.2.

\begin{tabular}{|c|c|}
\hline Publisher & 5-year total \\
\hline Elsevier & 21802 \\
\hline Springer Nature & $11353^{11}$ \\
\hline BMJ & 10411 \\
\hline Wiley & 10008 \\
\hline Oxford University Press (OUP) & 5201 \\
\hline SAGE Publications & 3248 \\
\hline Wolters Kluwer & 3141 \\
\hline Taylor \& Francis & 2507 \\
\hline Public Library of Science (PLoS) & 1272 \\
\hline Cambridge University Press (CUP) & 1099 \\
\hline Cold Spring Harbor Laboratory & 1038 \\
\hline American Society of Clinical Oncology (ASCO) & 973 \\
\hline Mark Allen Group & 973 \\
\hline American Society of Hematology & 902 \\
\hline Royal College of Surgeons of England & 669 \\
\hline Frontiers & 662 \\
\hline Royal College of Physicians & 638 \\
\hline MDPI & 560 \\
\hline Thieme & 435 \\
\hline RCN Publishing & 431 \\
\hline European Respiratory Society (ERS) & 419 \\
\hline National Institute for Health Research & 383 \\
\hline British Editorial Society of Bone \& Joint Surgery & 377 \\
\hline American Medical Association (AMA) & 361 \\
\hline Hindawi & 356 \\
\hline Royal College of Psychiatrists & 351 \\
\hline Karger Publishers & 349 \\
\hline Emerald & 288 \\
\hline American Society for Microbiology & 284 \\
\hline British Institute of Radiology & 275 \\
\hline AME Publishing Company & 270 \\
\hline Royal College of General Practitioners & 267 \\
\hline Mary Ann Liebert & 265 \\
\hline Future Science Group & 247 \\
\hline Faculty of 1000 & 209 \\
\hline
\end{tabular}

${ }^{11}$ Without further analysis it is not possible to report separately on Springer titles and Nature titles as Dimensions does not separate these.

22 |Recommendations about publishing and publication 


\begin{tabular}{|l|l|}
\hline Bioscientifica & 184 \\
\hline American Association for Cancer Research (AACR) & 179 \\
\hline IOS Press & 179 \\
\hline Microbiology Society & 177 \\
\hline IOP Publishing & 162 \\
\hline The Endocrine Society & 156 \\
\hline Association for Research in Vision and Ophthalmology (ARVO) & 155 \\
\hline American Diabetes Association & 151 \\
\hline Research Square & 151 \\
\hline European Centre for Disease Control and Prevention (ECDC) & 147 \\
\hline JMIR Publications & 146 \\
\hline American Thoracic Society & 145 \\
\hline Impact Journals, LLC & 139 \\
\hline Massachusetts Medical Society & 127 \\
\hline Baishideng Publishing Group & 120 \\
\hline
\end{tabular}

Table 4.2. Top publishers (authors from Arm's Length Bodies)

The top publishers remain fairly consistent by year (Fig. 4.2). The general upward trend shown by most is consistent with the overall upward trend in publications. 


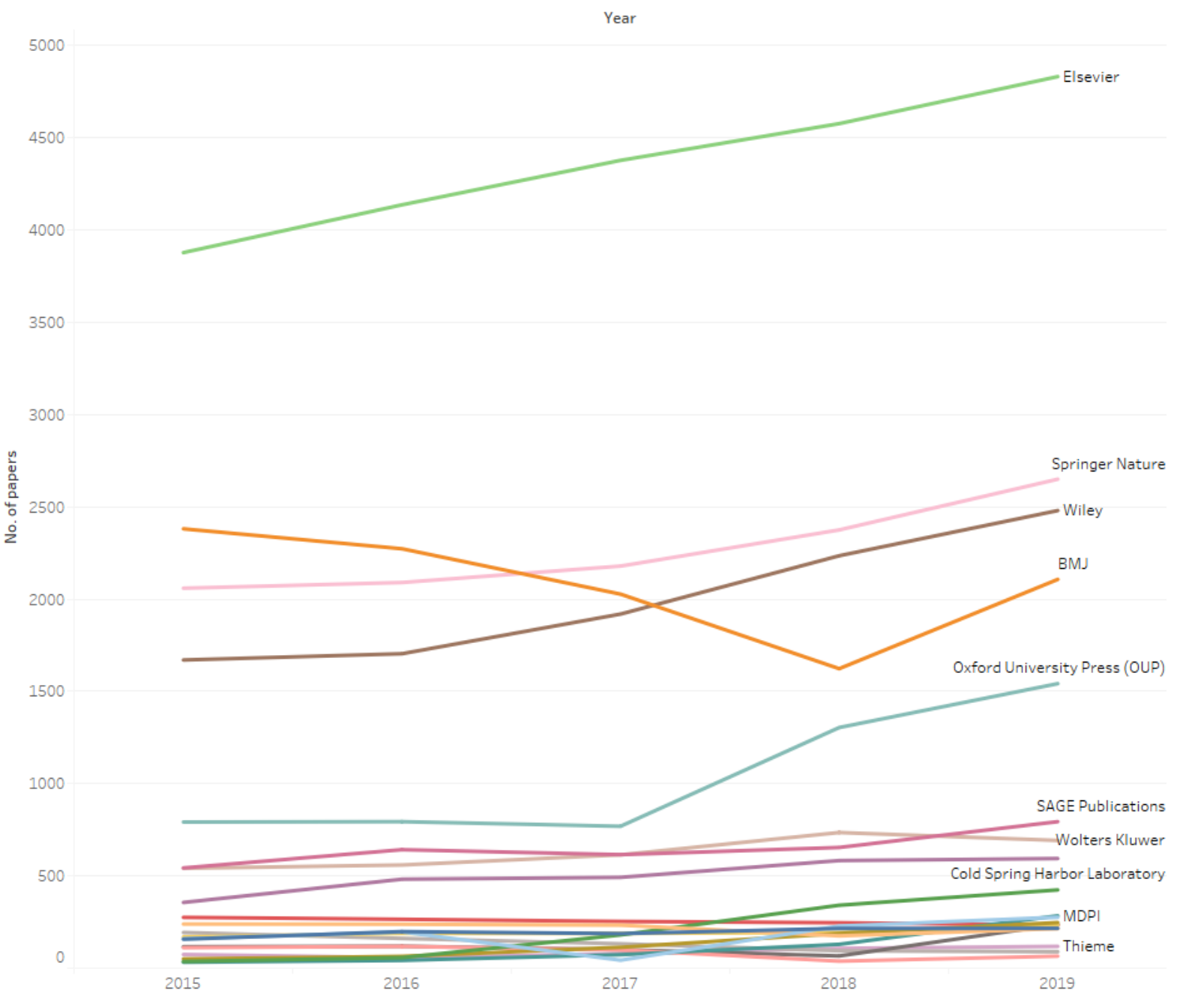

Fig 4.2. Top publishers by year.

NIHR associated articles

We then looked at the dataset of NIHR acknowledged or Researchfish reported journal articles. 53,253 papers were published in 4,280 journals. The top 50 journals are listed in Table 4.3. About half of these titles appear in the list ranked by author (Table 4.1).

\begin{tabular}{|l|r|}
\hline Journal & 5-year total \\
\hline Cochrane Database of Systematic Reviews & 1682 \\
\hline BMJ Open & 1558 \\
\hline PLoS ONE & 1319 \\
\hline Scientific Reports & 634 \\
\hline Trials & 602 \\
\hline The Lancet & 473 \\
\hline Health Technology Assessment & 424 \\
\hline The BMJ & 403 \\
\hline Nature Communications & 380 \\
\hline
\end{tabular}

24 IRecommendations about publishing and publication

procurement practices across the health and social caresystem.

An independent report by Information Power. 


\begin{tabular}{|c|c|}
\hline British Journal of General Practice & 305 \\
\hline BMC Public Health & 301 \\
\hline New England Journal of Medicine & 261 \\
\hline Rheumatology & 220 \\
\hline Thorax & 218 \\
\hline Brain & 209 \\
\hline British Journal of Cancer & 209 \\
\hline Psychological Medicine & 203 \\
\hline BMC Medicine & 202 \\
\hline BMC Health Services Research & 199 \\
\hline European Respiratory Journal & 198 \\
\hline Annals of the Rheumatic Diseases & 197 \\
\hline Health Services and Delivery Research & 191 \\
\hline Archives of Disease in Childhood & 176 \\
\hline Age and Ageing & 172 \\
\hline British Journal of Dermatology & 172 \\
\hline PLoS Medicine & 171 \\
\hline Health Expectations & 170 \\
\hline BJOG An International Journal of Obstetrics \& Gynaecology & 167 \\
\hline Nature Genetics & 167 \\
\hline BMC Psychiatry & 158 \\
\hline American Journal of Respiratory and Critical Care Medicine & 156 \\
\hline Heart & 156 \\
\hline Pilot and Feasibility Studies & 156 \\
\hline British Journal of Surgery & 154 \\
\hline Systematic Reviews & 147 \\
\hline International Journal of Cardiology & 144 \\
\hline International Journal of Epidemiology & 143 \\
\hline Journal of Affective Disorders & 143 \\
\hline Journal of Neurology Neurosurgery \& Psychiatry & 140 \\
\hline The Lancet Psychiatry & 140 \\
\hline Diabetic Medicine & 139 \\
\hline Proceedings of the National Academy of Sciences of the United States of America & 138 \\
\hline Journal of Allergy and Clinical Immunology & 136 \\
\hline British Journal of Haematology & 135 \\
\hline Neurology & 135 \\
\hline American Journal of Human Genetics & 132 \\
\hline The British Journal of Psychiatry & 132 \\
\hline Clinical Infectious Diseases & 131 \\
\hline European Heart Journal & 128 \\
\hline Human Molecular Genetics & 128 \\
\hline
\end{tabular}

Table 4.3. Top journals (NIHR funding)

25 |Recommendations about publishing and publication

procurement practices across the health and social care system.

An independent report by Information Power. 
These 4,280 journals are published by 290 different publishers. The top 50 publishers are listed in Table 4.4. Unsurprisingly, the top ten publishers are almost identical to those ranked by author affiliations, and while the ranking order varies further down the table, most of the names are the same.

\begin{tabular}{|c|c|}
\hline Publisher & 5-year total \\
\hline Elsevier & 10117 \\
\hline Springer Nature & 9906 \\
\hline Wiley & 8790 \\
\hline BMJ & 4063 \\
\hline Oxford University Press (OUP) & 2946 \\
\hline Wolters Kluwer & 1738 \\
\hline Public Library of Science (PLoS) & 1728 \\
\hline SAGE Publications & 1555 \\
\hline Taylor \& Francis & 1513 \\
\hline National Institute for Health Research & 786 \\
\hline Cambridge University Press (CUP) & 718 \\
\hline Frontiers & 518 \\
\hline MDPI & 396 \\
\hline American Medical Association (AMA) & 384 \\
\hline Royal College of General Practitioners & 324 \\
\hline European Respiratory Society (ERS) & 254 \\
\hline Faculty of 1000 & 248 \\
\hline JMIR Publications & 248 \\
\hline American Society for Microbiology & 227 \\
\hline American Association for Cancer Research (AACR) & 215 \\
\hline Royal College of Psychiatrists & 212 \\
\hline American Thoracic Society & 192 \\
\hline Mark Allen Group & 171 \\
\hline Massachusetts Medical Society & 167 \\
\hline Hindawi & 166 \\
\hline Mary Ann Liebert & 164 \\
\hline American Diabetes Association & 158 \\
\hline Karger Publishers & 145 \\
\hline American Association for the Advancement of Science (AAAS) & 139 \\
\hline American Chemical Society (ACS) & 139 \\
\hline Proceedings of the National Academy of Sciences & 138 \\
\hline The Endocrine Society & 138 \\
\hline Institute of Electrical and Electronics Engineers (IEEE) & 129 \\
\hline
\end{tabular}




\begin{tabular}{|l|l|}
\hline Future Science Group & 127 \\
\hline IOP Publishing & 119 \\
\hline Association for Research in Vision and Ophthalmology (ARVO) & 117 \\
\hline Impact Journals, LLC & 109 \\
\hline Royal Society of Chemistry (RSC) & 109 \\
\hline American Society of Hematology & 108 \\
\hline American Society for Clinical Investigation & 100 \\
\hline British Editorial Society of Bone \& Joint Surgery & 95 \\
\hline eLife & 93 \\
\hline Royal College of Physicians & 92 \\
\hline Thieme & 91 \\
\hline IOS Press & 89 \\
\hline American Physiological Society & 78 \\
\hline Bioscientifica & 78 \\
\hline American Psychological Association (APA) & 76 \\
\hline The Journal of Rheumatology & 75 \\
\hline American Society of Clinical Oncology (ASCO) & 74 \\
\hline
\end{tabular}

Table 4.4. Top publishers (NIHR funding)

Although we have not plotted these by year, we fully expect that the same patterns would be seen. While individual journals will vary from year to year, the top publishers will remain fairly consistent over time.

\section{What proportion of the articles are Open Access?}

85,542 papers (70\%) of the combined dataset were published Open Access which means they are freely available for anyone in the world to access and read.

There are two main approaches to deliver OA. Either content is made freely available for all to read and re-use because publishing costs have been paid upfront and a reuse license is attached or content is freely available for all to read because a near-final draft has been shared publicly, usually after a period of time has passed. Publishers tend to own or control the rights in these articles, and occasionally these papers come with clear user licenses which often restrict reuse to noncommercial users.

Each of these two main approaches can be further subdivided:

\begin{tabular}{|l|l|}
\hline Publishing costs have been paid upfront & $\begin{array}{l}\text { Near-final draft has been shared publicly, after } \\
\text { a period of time }\end{array}$ \\
\hline $\begin{array}{l}\text { Gold - costs typically paid by author from } \\
\text { research grants }\end{array}$ & $\begin{array}{l}\text { Green - a version of the article (either the } \\
\text { manuscript as originally submitted or as } \\
\text { accepted, or the final published version) is }\end{array}$ \\
\hline
\end{tabular}

27 Recommendations about publishing and publication procurement practices across the health and social caresystem. An independent report by Information Power. 


\begin{tabular}{|l|l|}
\hline & $\begin{array}{l}\text { shared via an institutional repository or subject } \\
\text { repository }\end{array}$ \\
\hline $\begin{array}{l}\text { Platinum - costs typically paid by employer, } \\
\text { funder, or another sponsor often with a per- } \\
\text { article charge }\end{array}$ & $\begin{array}{l}\text { Bronze - a version of the article is shared via } \\
\text { the publisher's site }\end{array}$ \\
\hline $\begin{array}{l}\text { Diamond - costs typically paid by employer, } \\
\text { funder, or another sponsor without any per- } \\
\text { article charge }\end{array}$ & \\
\hline
\end{tabular}

$19 \%$ of all papers were published as Gold OA, and 15\% as hybrid OA. 19\% were published and made available as Green OA, and $17 \%$ as Bronze.

Fig 5.1 shows these figures broken down by year for the four organisations with the highest publication volumes. The proportion of papers published as OA has been gradually increasing over time. This is particularly so for Gold and Hybrid OA and is also observable for the various flavours of Green taken together. This is very much in line with what we would expect to see over this period. The uptick in closed articles seen for 2019 is most likely a timing issue; a 12 month embargo period is common for some types of $\mathrm{OA}$, so a number of papers currently showing as closed will be made available as Green or Bronze in due course.

The same trends can be seen in the organisations with fewer publications, although they are largely drowned out by noise in those publishing very few papers.

\begin{tabular}{|l|}
\hline OA type \\
Pure Gold \\
Hybrid \\
Green, Published \\
Green, Accepted \\
Green, Submitted \\
Bronze \\
Closed \\
\hline
\end{tabular}




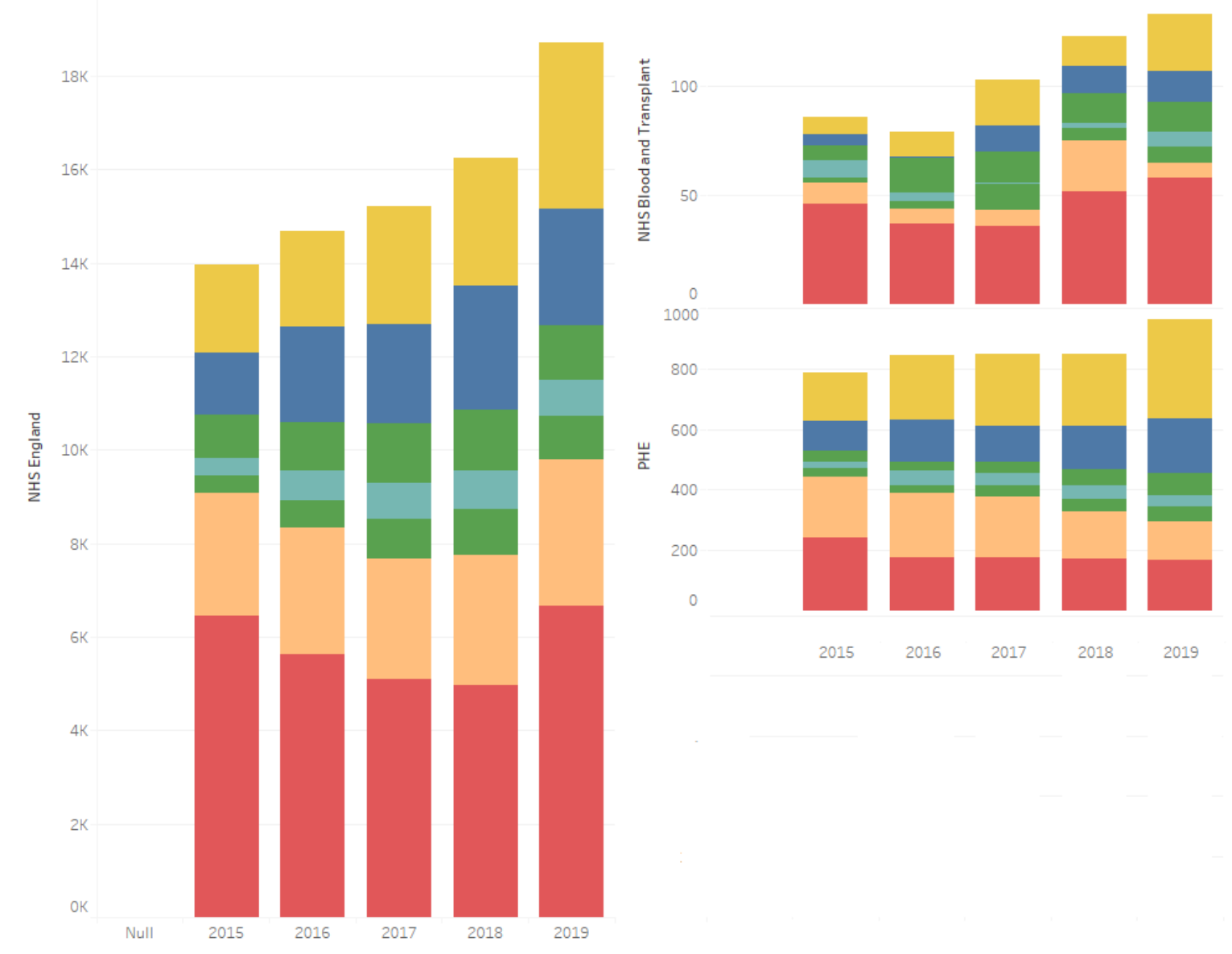

Fig 5.1. OA by year for the highest-publishing organisations

We also looked at the OA proportions in the dataset of papers funded by NIHR, looking at where the corresponding authors only were employed. Corresponding author information is available only for a proportion of the data, predominantly papers published by Elsevier and Springer. These two publishers account for $37 \%$ of the total dataset. Both publishers offer OA options, so this data has been used to estimate proportions of OA choices made by corresponding authors. It should be noted that, as approximately $3 \%$ of papers are published with PLOS, and probably another couple of percent with other OA-only publishers, the estimates here probably understate the total amount of Gold OA by $5 \%$ or so. Again, an uptick in closed content is visible in 2019 , for the same reasons as noted above. 


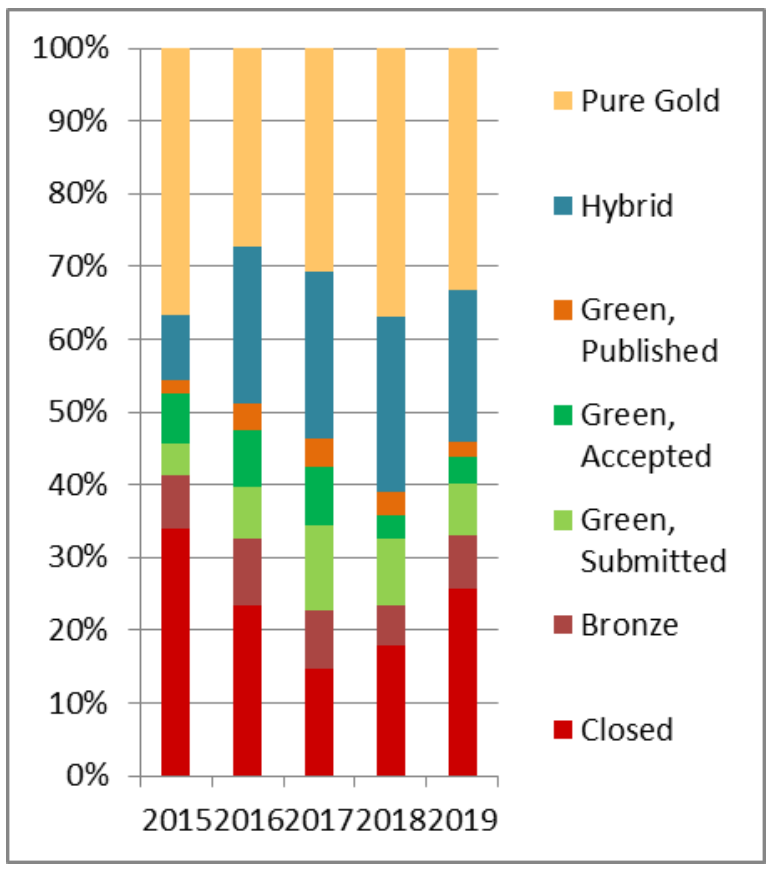

Fig. 5.2 OA proportions year on year categorised by corresponding author. (a) NHS England

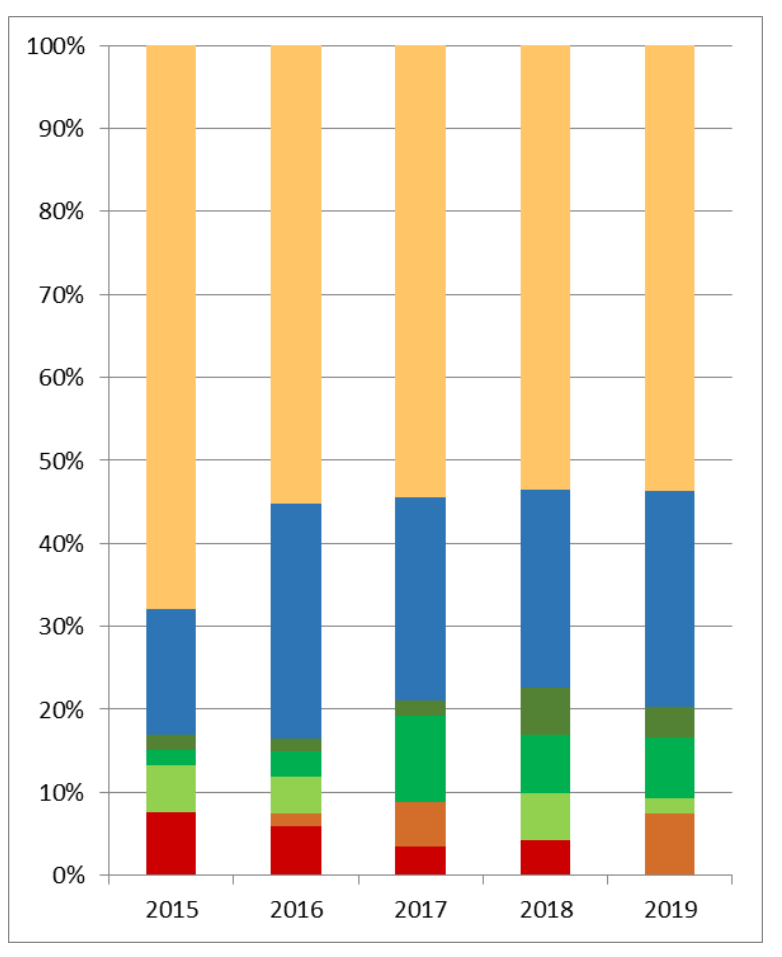

Fig 5.2(c) Other UK universities

30 |Recommendations about publishing and publication

procurement practices across the health and social care system.

An independent report by Information Power. 


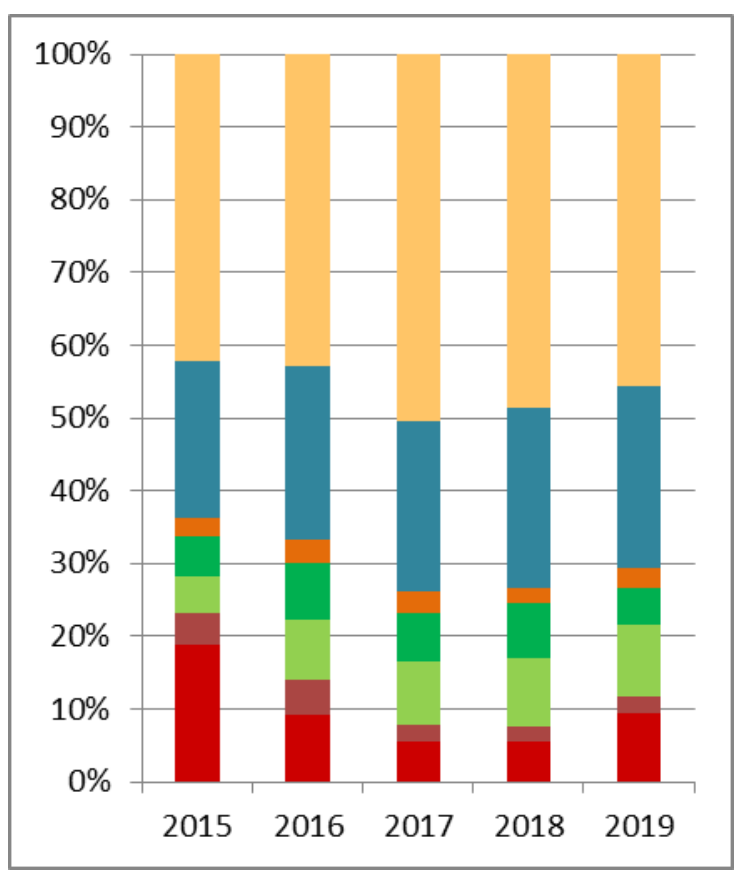

Fig. 5.2(b) English universities

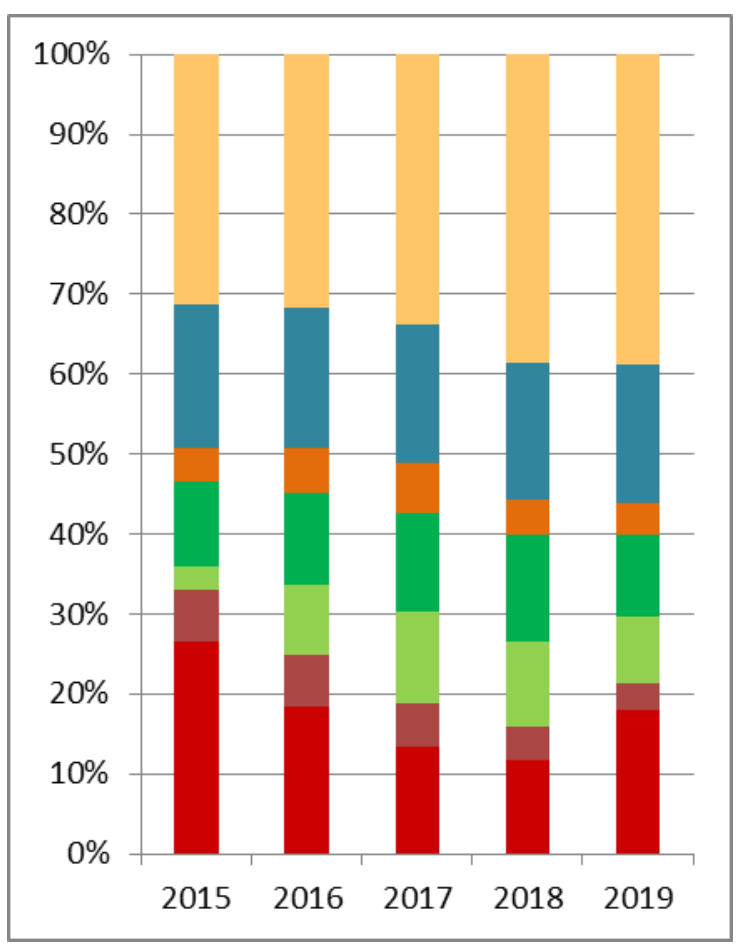

Fig 5.2(d) Overseas universities

31 Recommendations about publishing and publication

procurement practices across the health and social care system.

An independent report by Information Power. 


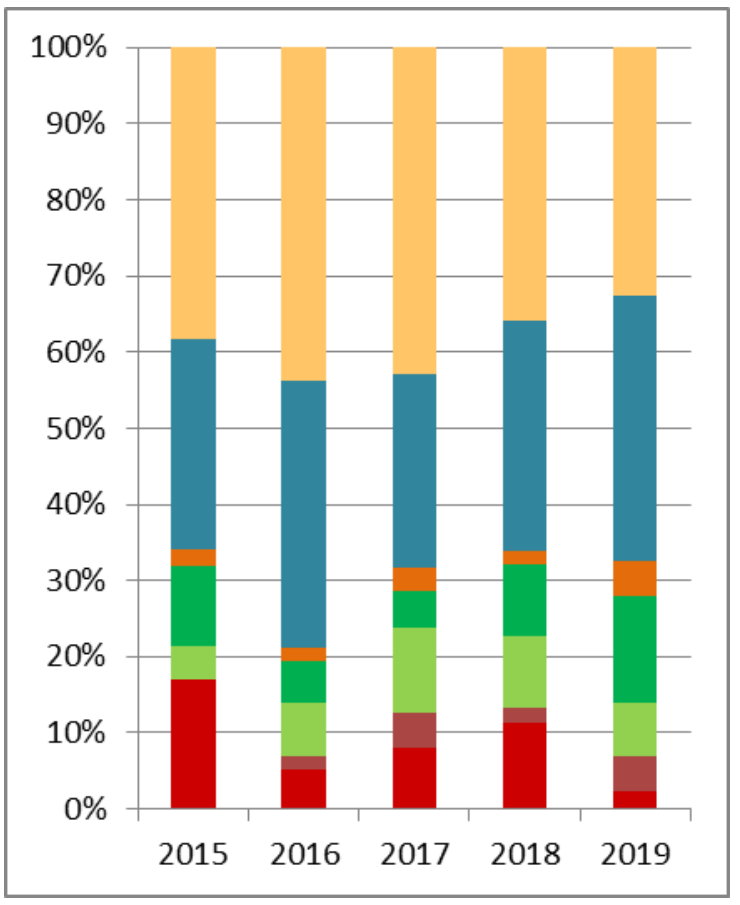

Fig. 5.2(e) Not for Profit

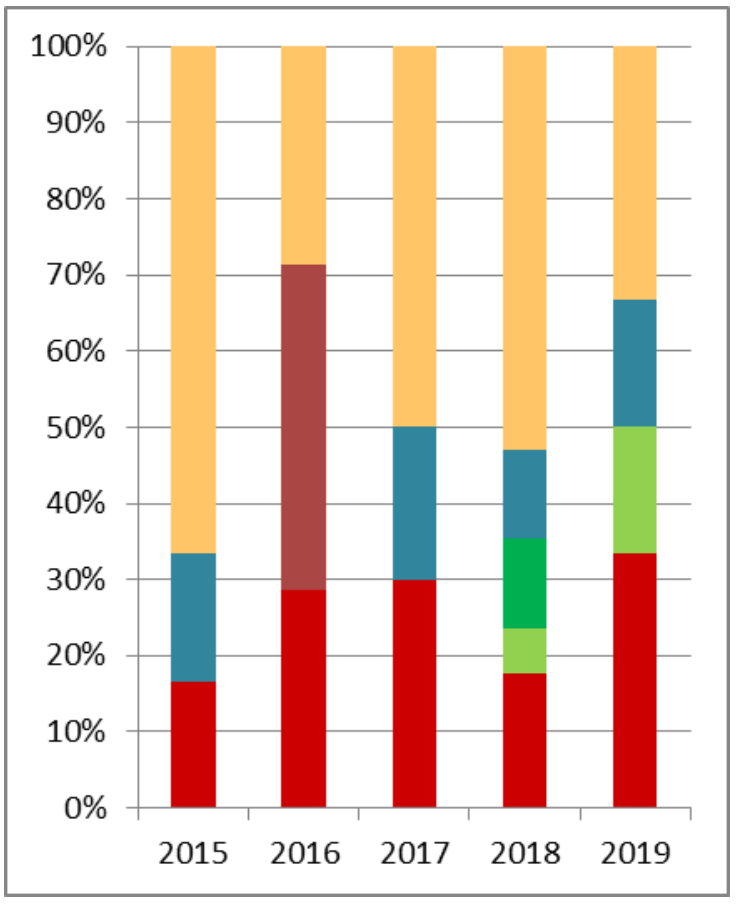

Fig. 5.2 (g) PHE (note that this graph is based on very limited data)

32 |Recommendations about publishing and publication procurement practices across the health and social caresystem. An independent report by Information Power. 


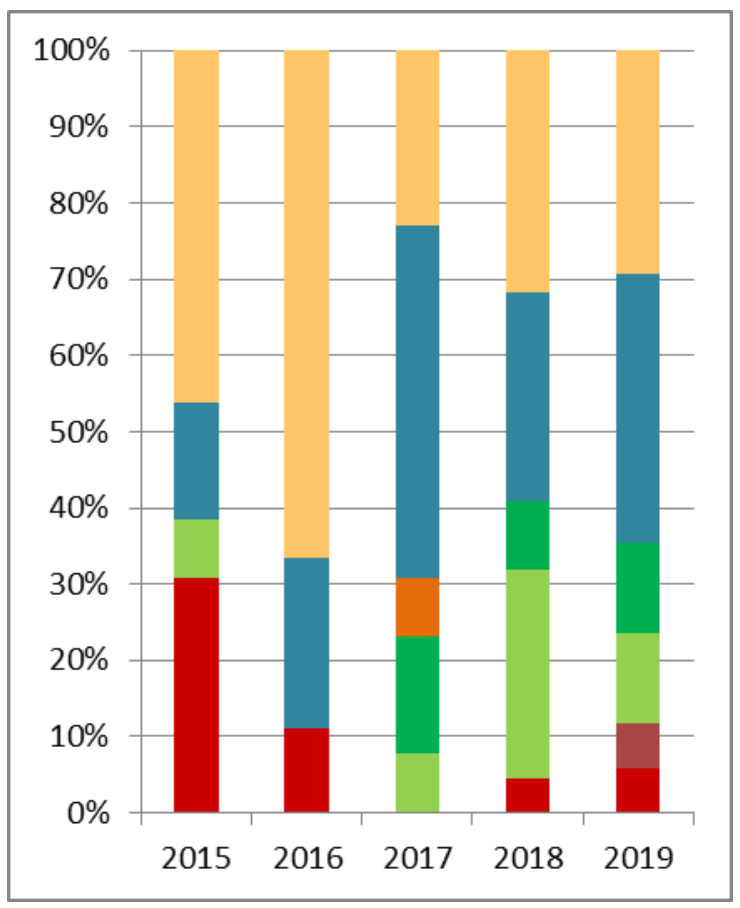

Fig. 5.2(f) Industry

6. What proportion of the papers have co-authors that are UKRI-funded?

$17 \%$ of papers with a co-author from the health and social care system reported having UKRI funding (Table 6.1).

\begin{tabular}{|lrrr|}
\hline & UKRI funding & Total publications & Proportion \\
\hline NHS in & & & \\
England & 9996 & 78791 & $13 \%$ \\
PHE & 799 & 4295 & $19 \%$ \\
NHS B\&T & 90 & 524 & $17 \%$ \\
NICE & 22 & 368 & $6 \%$ \\
DHSC & 51 & 359 & $14 \%$ \\
MHRA & 49 & 317 & $15 \%$ \\
HEE & 3 & 333 & $1 \%$ \\
NHS D & 51 & $10 \%$ \\
CQC & 5 & 51 & $6 \%$ \\
NHS I & 3 & 71 & $0 \%$ \\
HRA & 0 & 22 & $32 \%$ \\
HTA & 7 & 2 & $50 \%$ \\
HFEA & 1 & 4 & $50 \%$ \\
NHS BSA & 2 & 3 & $0 \%$ \\
NHS R & 0 & 5 & $0 \%$ \\
Total & 0 & $\mathbf{1 0 3 7 2 2}$ & $\mathbf{1 7 \%}$ \\
\hline
\end{tabular}

Table 6.1. Proportion of papers with UKRI funding

7. What proportion of the papers have co-authors funded by other UK funders?

33 |R e commendations about publishing and publication

procurement practices acrossthe health and social caresystem.

An independent report by Information Power. 
$19 \%$ of papers with a co-author from the health and social care system reported having other UK funding (Table 7.1).

\begin{tabular}{|c|c|c|c|}
\hline & Other UK funding & Total publications & Proportion \\
\hline $\begin{array}{l}\text { NHS in } \\
\text { England }\end{array}$ & 12397 & 78791 & $16 \%$ \\
\hline PHE & 784 & 4295 & $18 \%$ \\
\hline $\begin{array}{l}\text { NHS } \\
\text { B\&T }\end{array}$ & 136 & 524 & $26 \%$ \\
\hline NICE & 25 & 368 & $7 \%$ \\
\hline DHSC & 46 & 359 & $13 \%$ \\
\hline MHRA & 47 & 317 & $15 \%$ \\
\hline HEE & 4 & 333 & $1 \%$ \\
\hline NHS D & 6 & 51 & $12 \%$ \\
\hline CQC & 5 & 51 & $10 \%$ \\
\hline NHS I & 3 & 71 & $4 \%$ \\
\hline HRA & 5 & 22 & $23 \%$ \\
\hline HTA & 0 & 2 & $0 \%$ \\
\hline HFEA & 0 & 4 & $0 \%$ \\
\hline $\begin{array}{l}\text { NHS } \\
\text { BSA }\end{array}$ & 1 & 3 & $33 \%$ \\
\hline NHS R & 0 & 5 & $0 \%$ \\
\hline Total & 19895 & 103722 & $19 \%$ \\
\hline
\end{tabular}

Table 7.1. Proportion of papers with co-authors funded by other UK (non-UKRI) funders

\section{Preprint posting by authors within the health and social care system}

Dimensions lists 1224 preprints posted by authors within the health and social care system in this group of manuscripts, posted in five places (Table 8.1).

\begin{tabular}{|lr|}
\hline Preprint archive & No. \\
bioRxiv & 966 \\
medRxiv & 30 \\
PeerJ Preprints & 18 \\
Research Square & 151 \\
SSRN Electronic Journal & 59 \\
Total & 1224 \\
\hline
\end{tabular}

Table 8.1

Only NHS in England, NIHR and PHE published any significant numbers of preprints (Fig. 8.2) 


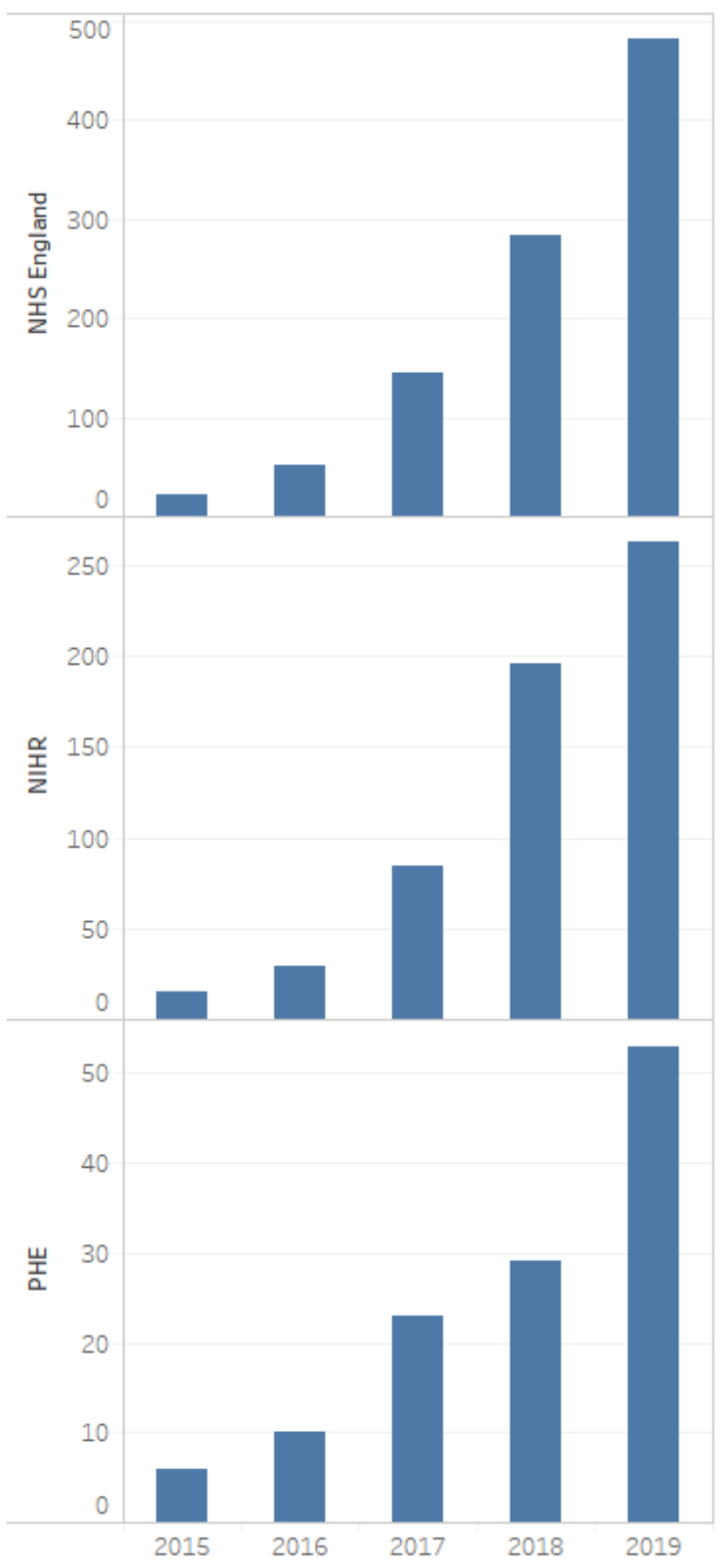

Fig 8.2. Preprints by year for NHS in England, NIHR and PHE. NB: NIHR preprints are by authors who incorrectly identify NIHR as their employer rather than as their funder.

There is a clear and rapid upward trend in the number of preprints published from a very small base. Some of the other organisations published a few preprints, clustered towards the more recent years (Table 8.2). NHS Digital, CQC, HRA, NHS Resolution, HFEA and HTA published none.

\begin{tabular}{|l|l|l|l|l|l|l|l|}
\hline & $\begin{array}{l}\text { NHS } \\
\text { B\&T }\end{array}$ & NICE & DHSC & HEE & MHRA & $\begin{array}{l}\text { NHS } \\
\text { Improvement }\end{array}$ & $\begin{array}{l}\text { NHS } \\
\text { BSA }\end{array}$ \\
\hline 2015 & & & & & & & \\
\hline 2016 & 3 & & & & & & \\
\hline 2017 & 1 & & & & & & \\
\hline
\end{tabular}

35|Recommendations about publishing and publication procurement practices acrossthe health and social caresystem. An independent report by Information Power. 


\begin{tabular}{|r|r|r|r|r|r|r|r|}
\hline 2018 & 4 & & 1 & & 2 & & \\
\hline 2019 & 9 & 0 & 1 & 3 & 0 & 1 & 1 \\
\hline
\end{tabular}

Table 8.2. Number of preprints published

\section{What proportion of papers have a corresponding author from the UK health and social care} system?

Dimensions holds corresponding author information for certain publishers, including Springer Nature and Elsevier. This information is present for $30 \%$ of the articles in the author-based dataset and offers a reasonable estimate of the picture overall.

$37 \%$ of the sample had a corresponding author affiliated to NHS England, and 1.5\% to Public Health England. Numbers for the other organisations were all lower than $0.1 \%$.

Since the data is concentrated on UK and international publishers, one would anticipate that these figures would be a maximum estimate (a paper in a US journal, for example, is comparatively more likely to be an international collaboration with a US corresponding author). A number of corresponding authors report dual affiliations (typically, a university post and an NHS hospital post). The figures have taken an inclusive approach - in such examples they would be assigned to NHS in England), so again this would represent an upper bound to the figures. 


\section{Appendix 3 - Data collection template}

To inform your negotiations with publishers we recommend that you require the primary publishers to which HEE currently subscribes to provide you with the data which will inform an important part of your ongoing negotiations with them and your collections strategy. The data template should be sent to the relevant publishers with the following instructions.

\section{Instructions}

We are interested in understanding our journal relationship with you more fully, and respectfully request that you consider providing us with some data to help us understand this. We are interested in both access to journals for reading and our publications in your journals.

To help get you started the data collection template is prepopulated with our organisation names and GRID identifiers.

Worksheet 1

First, we ask you for your organisation's official name (B2)

Columns $\mathbf{C}, \mathbf{D}$, and $\mathbf{E}$ ask for your annual subscription expenditure with each publisher. If it is easier for you, then it is ok to report instead on financial years but please make a note of this in column $\mathbf{N}$. We assume that your subscription expenditure is to access journals for reading, but if the subscription expenditure also pays for any publishing please make a note of this in column $\mathbf{N}$.

Column $\mathbf{F}$ asks about the number of subscribed titles in the current year. Please include this if you know the number, but don't worry too much if you do not have this information.

Column $\mathbf{G}$ asks whether your agreement is aligned with the NHS procurement framework. Please enter $\mathrm{Y}$ for yes, $\mathrm{N}$ for no, or? if you are unsure.

Columns $\mathbf{H}-\mathbf{M}$ ask about your expenditure to publish journal articles with these publishers. We are asking specifically about article-level open access expenditure with the publishers (i.e. Article Processing Charges or APCs). If you have other OA expenditure with the publishers (e.g. OA membership schemes, Read and Publish agreements, Subscribe to Open agreements, or other socalled OA transformative agreements) or other publication fees (e.g. colour charges, page charges) please note this and the level of expenditure for these in column N. Again, we ask for annual subscription expenditure with each publisher, but it is ok to report instead on financial years if this is easier for you. If you do this, please make a note in column $\mathbf{N}$.

Column $\mathbf{N}$ can also be used to tell us about any other things you would like to share. For example, about any advice or guidance you provide to your employees about open access publishing or any income you may receive from these publishers.

Please ensue that you total the columns in the template, so your negotiating partner can easily see the total subscription spend in previous years and the total APC spend. If you have given APC waivers to authors from the consortium, make sure your negotiating partner is aware. If this is the first time you have worked with the consortium, your legacy pricing for individual universities might surprise. Explain why historic pricing may look uneven - perhaps because some institutions take more journal titles than others, or perhaps some take print and others do not. Be transparent about any anomalies and how you plan to resolve them.

The Data collection template is an Excel spreadsheet at Annexe A.

37 IRecommendations about publishing and publication

procurement practices across the health and social caresystem.

An independent report by Information Power. 


\section{Appendix 4 - Current expenditure}

Some Arm's Length Bodies have a small library budget for journals, document supply, and databases. These libraries provide a top up service and rely very heavily on HEE's purchase of the Core Content Collection. They struggle to afford a great deal of content and find that publishers use irrelevant metrics like total employee numbers or number of beds. Librarians in this sector do not feel qualified to understand new OA journal agreements and feel that they already "are jumping so many hoops to get the journal for access at a reasonable price."

We asked all the Arm's Length Bodies to complete a data collection template to enable us to understand their current expenditure with publishers. We received:

- 3 completed templates from NHS Blood \& Transport, NHS Business Services Authority, and NICE

- An early 2019 audit report of electronic resource and systems expenditure by NHS Libraries, not all spend was declared within this report and how much is missing is unclear

- Aggregated three-year expenditure data for the Core Content Collection, a centrally procured collection of primary journals, aggregated databases, and abstract and indexing databases.

These data suggest that the Arm's Length Bodies spend c. f800k per annum on primary journal subscriptions, an amount equivalent to a single medium sized UK university ${ }^{12}$ :

- NHS BSA subscribes to the Health Services journal and seems to have renegotiated a deal recently.

- NHS B\&T spend $f 34 k$ p.a. on journals from six publishers, with the biggest spend ( $f 13 k$ ) on the American Society of Hematology.

- $\quad$ NICE spends $£ 15 k$ p.a. on journals from eight publishers, with nearly half spent on one title from the American Medical Association and four titles from Wiley.

- Far more significant is the Core Content Collection, funded by HEE and procured by NICE. Approximately $f 750 k$ per year is spent on journal content from one publisher, and a further $£ 2.25 \mathrm{~m}$ per year is spent on aggregated and abstract \& indexing databases.

There was only very modest additional expenditure by these organisations for Open Access

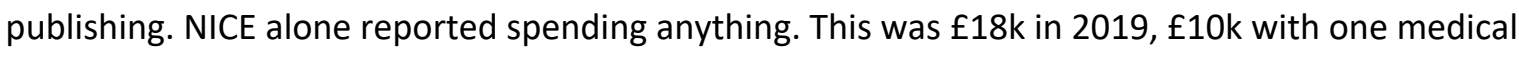
publisher and the remainder being one-off articles. NIHR, of course, is the chief funder of OA publishing for the sector as money to cover these costs are allowed within grant proposals. Unfortunately, because of the way grant funding is tracked, NIHR is currently unclear precisely how much it spends on APCs.

Between them, NHS in England and PHE account for $98 \%$ of article publishing activity, with the lion's share (92\%) belong to NHS in England. Between them, NHS Blood \& Transport and NICE account for just over $1 \%$ of all the publishing activity.

Any significant attempt to negotiate OA deals with publishers would need to focus on NHS in England, PHE, and NIHR - ideally working together in partnership so that subscription spend by one and $O A$ spend by the other are brought together.

\footnotetext{
${ }^{12}$ Lawson S and Meghreblian B. Journal subscription expenditure of UK higher education institutions [version 2; peer review: 4 approved]. F1000Research 2014, 3:274

(https://doi.org/10.12688/f1000research.5706.2)

38 I Recommendations about publishing and publication

procurement practices across the health and social care system.

An independent report by Information Power.
} 


\section{Appendix 5 - Overview of interviews and focus groups}

Ten interviews and three focus groups were organised with researchers, research managers and library and information professionals. We also drew on a survey of UKRD research leaders ${ }^{13}$ by Nick McNally which echoes many of our findings.

Discussions with participants from such a range of roles and institutions resulted in a range of views, however there were common threads that ran through the interviews. These are:

1. There is a commitment to the principles of Open Access. The librarians, researchers, and research managers we engaged with were committed to OA.

"Some grants require this, I am a Crown Servant, and this is required for work that PHE leads, and in any case, I prefer it morally and practically. Practical: more downloads and citations, easier to share on social media and in a way that provides more nuance than simply sharing an abstract could. Philosophical: democratisation of knowledge, public should have access to publicly funded research without paying $£ 35$ pay-per-view prices. The only downside is cost, although sometimes these can be covered."

"Open access publishing is very important and very helpful. Means that the research is accessible to a wider audience. Main downside is that every publication incurs an open access charge now, whereas previously, in many journals, publication was free. This cost is borne by the research funder usually but is often an issue where it is a medical student project or a publication arising from a thesis, where they may not be earmarked funds."

"Everyone - me and my supervisors - are supportive of OA, so money is the main issue." "I am all for OA! It is crucial for clinical trials to be open too. Open access and open peer review can help drive up standards. Open access facilitates patient access. Subscribing to journals is an expensive waste of time. And it can be very hard to publish about unusual diseases and also about negative results."

"The only other thing I would add is the extent to which research summaries are able to draw together the research available in terms of synthesis and how various articles link, or not, to journal articles. What is made available through open access can cut through the noise rather than add to it. This is to the benefit of local communities, service users and providers."

"There is a disconnect because research is led by academics. Others can't see the research outputs until they are published. Clinical staff do not get to read this research, because we do not have access to journals."

2. Cost of APCs is a barrier. Researchers and research managers felt that there is a need for sufficient central funding, easily accessed at the point of publication. While some research grants do indeed cover OA publication charges, there are challenges in estimating these costs to build into grant applications. At that stage researchers do not know how many articles will result nor which journals these will be published in and what the journal's APC will be. They can guess based on an average number of articles previously produced in year, but it is hard to get this right.

${ }^{13}$ http://www.ukrdleaders.org/2020/10/05/open-access-is-on-the-agenda/

39 |Recommendations about publishing and publication procurement practices across the health and social caresystem. An independent report by Information Power. 
"Applied Research Collaboration (ARCS) were preceded by CLARCs and we were about mid-way through our CLARC agreement when the NIHR OA mandate came in, but we didn't get any additional funding to implement it. Publishing all our research outputs $O A$ would have required nearly our entire $f 1.8 \mathrm{~m}$ research budget, so we have capped funding at 2 articles/PI. We now ask PIs to include costs for OA but that means of course there is less money available to them for research. Our assumption when the NIHR mandate came out is that NIHR would have a central budget somewhere that PIs would go to for their OA publishing costs."

"There is never enough funding. Some articles are covered by more than one grant, and this can help."

"Extend the NIHR policy on OA funding to all the Arm's Length Bodies."

"Do not place OA burdens on unfunded researchers who are doing proof of concept work."

"I try to negotiate APC prices down and/or apply for waivers. Then I consider which titles to submit to, because if I go with a Society title when I am a member of the Society then I can often get a 10 or $20 \%$ discount on APCs. Sometimes I'll ask one of the charities I work with for one-off funding for APC payments. There are some small departmental funds I can apply for, but this money is hard to come by. Sometimes I will discuss with co-authors which of us should be the corresponding author as their universities might have OA agreements with different publishers that means we can publish APC free. NHS co-authors don't have this, unfortunately."

"Over the past year, I've been asked for $£ 30 \mathrm{k}$ worth of open access publication costs related to CLARC research. And where am I supposed to find $f 30 \mathrm{k}$ due to timing delays and publications? I've paid it but it's a lot of money just to pull out of a hat."

"We receive multiple emails from clinicians each month who need publications to advance their careers and have no HEl co-authors. They need to enter their publications for advancement through the NHS, but there is no support structure for them to publish and specially to publish OA."

"One of the impacts of the original funder OA policies was to encourage publishers to increase their APC prices which exacerbates the situation."

"I found it especially hard to find funding to publish my PhD research [on epidemiological modelling] and had to rely on my supervisor and his grants."

"The Trust wants to do more in terms of home-grown research and struggles with enabling clinicians to publish research if a project has not got NIHR funding. Has some funding for OA publications for researchers/clinicians not allied to a university, but worried about opening the flood gates."

"Aspiring or early career clinical academics, particularly those in non-teaching hospital trusts or in primary care, can find publication costs a barrier if they are not part of a large academic unit or a team in receipt of a research grant with funding for this. Already being a published author is important when applying for early career fellowships e.g. NIHR In-practice fellowships, doctoral fellowships. However, accessing funding for open access fees is difficult. NHS organisations in receipt of NIHR Research Capability Funding (RCF) can award funding to individuals to pump prime the development of an NIHR funding application e.g. undertake a literature review or auditing and benchmarking current practice e.g. practitioner survey. They would then want to

40 IRecommendations about publishing and publication procurement practices acrossthe health and social caresystem. An independent report by Information Power. 
publish this work. However, NIHR RCF policy states that RCF cannot be used for dissemination activities yet this is a key source of funding for many NHS researchers to support research capacity and capability development and publication is a key part of this. Could NIHR / DHSC review their NIHR RCF guidance to support open access publication?"

3. Researchers affiliated to, or collaborating with someone affiliated to, universities have a much easier time. However, for researchers without an HE affiliation, funding for OA publication can be difficult to obtain. Trust employees with academic affiliations get OA support. However, OA publishing services for Trust-only employees is never funded. Universities pay OA for their own researchers but not for NHS Trust staff.

"Universities barely have enough money to pay OA for their own researchers let along NHS Trust staff. HE librarians don't have capacity to manage NHS staff OA fees. Content by their own staff is not available to NHS because of the paywall, but it is not seen to be in the NHS interest to make this content available OA."

"I really appreciate my university's agreements with publishers which mean I can publish articles without needing to find money for APCs."

"There are generally higher levels of awareness of OA in HEls, and therefore in NHS Trusts that are closely affiliated with HEIs."

"The university has an OA policy, and provides support to answer questions about OA publishing or to self-archive in our repository. The Trust does not and does not provide any funding or guidance on OA to employees. This is not covered by our SLA or current budget. So, if a researcher is fully employed by the Trust, or if one of their projects if for the Trust only, then any articles flowing from this research would not be covered by our policy or practice."

"I try to prioritise the relevant Springer and Wiley titles as my university has OA agreements with them, and I can publish without paying APCs. OUP publishes another relevant title, but there is no university agreement with them."

"I am really passionate about embedding research in the NHS. Proper affiliation to HE institutions for anyone in higher training (e.g. Registrars) is essential for good access to literature and for publishing. In my higher training I needed to have 3 first-authored papers as part of my requirements. If OA funding were available systematically for NHS people in higher training, then it would probably be possible to get these articles into better journals."

4. Central funding, for example block grants, would drive beneficial change. In HE, libraries manage block grants which as well as paying for APCs, can contribute funding to OA journal agreements which enable APC-free open access publishing by affiliated authors. It is not only the availability of central funding for these agreements that is powerful, but also the institutional visibility and responsibility for compliance that drives valuable change and an increase in OA publishing by researchers.

"We need an incentive like a REF for Trust-based research to get the attention of Chief Executives so that they own and drive OA strategies."

41 Recommendations about publishing and publication procurement practices across the health and social caresystem. A n independent report by Information Power. 
"Give us central funding like in universities. For example, in an ARC it would be helpful if we had funding on top of what we'd already got that is specifically for OA."

"OA fees are charged against direct costs of research projects, and if there is a budget shortfall NIHR has a process by which the researcher can apply for extra financial support. The budget is left open for one year after the project finishes for this purpose. This is great in principle but in practice this creates enormous extra costs to us as it is complex to manage in our finance and other systems."

"Block grants enable us to provide OA advocacy, education, and support which is essential in driving awareness of funder OA requirements and to delivering compliance."

"Block grants mean OA funds come straight to the library where they can be properly managed and properly leveraged to drive change. If NIHR OA funding goes straight to researchers, then micromanaging it and them would be so difficult that it simply would not happen. Block grants provide funding so that we can provide a broad array of training, OA advocacy, institutional repository services, as well as APC funding and Read \& Publish agreements."

5. Engagement with publishers needs to be strengthened. The focus group with library professionals revealed that journals are acquired through a mixture of national procurement via NICE, direct purchase by Trusts, and national or regional consortia (e.g. Jisc, SUPC, collaborative purchasing by organisations in London for medical resources). Some Arm's Length Bodies have a small library budget for journals, document supply, and databases. These libraries provide a top up service and rely very heavily on HEE's purchase of the Core Content Collection. Several librarians and research managers mentioned a Jisc project done in 2016 which suggested that for an additional investment of $f 1-2 m$ per annum all the relevant journals needed in the health and social care system and available in universities could be provided ${ }^{14}$.

"Access to literature is problematic. NHSE provides journal access, but as a surgeon the titles are a bit disappointing. Scotland provides much better selection of journals for surgeons."

"The CCG has no library service. One of the reasons I have an honorary position with the university is so I can access the library resources. As a result of the lack of library services, clinicians do not know how to do research and do not have the support of a librarian."

"It should be mandatory that CCGs have access to library services."

"Change the way prices are agreed with publishers. Rather than using irrelevant metrics like total employee numbers or number of beds, explore usage-based pricing. Secure price decreases as the proportion of OA content in a journal increases. Secure discounts based on the number of free authors, reviewers, and editors we have provided to them."

\footnotetext{
${ }^{14}$ https://community.jisc.ac.uk/groups/nhs-he-forum-connectivity-project/document/nov-16-jisc-collectionsnhs-finch-pilot-outcomes

42 |Recommendations about publishing and publication procurement practices across the health and social care system. An independent report by Information Power.
} 
"What would make it easier for me to publish my articles OA? Money for OA in the form of adequate funding, or better still more university agreements that mean I can publish OA without paying APCs. Could NIHR do these agreements to cover publishing by its grant recipients?"

\section{There is need for education and training for all stakeholders. For example:}

- Some of the research managers in the NHS in control of budgets which could be used for OA publication, were reluctant to do so because they feared that the NHS research budget is somehow hijacked by academic researchers, who want to publish to further their careers, rather than to make things better for patients.

- There is evidence that some researchers in the health and social care system struggle to identify whether or not a journal is predatory

- About copyright and licensing of content published within the health and social care system, including by Arm's Length Bodies on their websites.

- To raise awareness of responsible research metrics and limit the influence of a journal impact factor on researcher decisions about where to publish.

- To address perception of all open access publications as 'low quality' or vanity publishing because there is a fee paid by the authors or their organisations.

\section{New forms of $O A$ are relevant.}

"In our field it is common to post preprints even before you decide where to submit your article, and this is even more the case since Covid 19. This can result in a requirement to publish an article OA. I tend to deposit preprints in medRxiv."

"We would like to see immediate green OA as a compliant route."

"The Ambulance Service has an institutional repository, but it is early days for this service."

"If researchers want to publish OA and don't have OA funding, then we advise them to see if any of their co-authors have an academic affiliation or to consider depositing a manuscript in Zenodo as we don't have an institutional repository."

"It would be great to have a statement from DHSC/NIHR to embrace principles of open publication and open clinical trials too."

"OA rights retention would be really helpful, from a library perspective."

"NIHR could helpfully sign up to DORA."

\section{OA is essential but not enough in itself.}

"Very pressurised NHS jobs leave very little time for any of us to read articles... We also need simple lay summaries."

43 I Recommendations about publishing and publication

procurement practices across the health and social caresystem.

An independent report by Information Power. 
"In order to increase impact, we publish quite a lot ourselves via the web on our ARC Implementation Hub - press releases, documentation of our own, booklets, infographics, videos. Everything is free."

"Need to drive implementation and impact of research which means action-oriented summaries of research are needed."

"There may still be researchers employed in local government, but they will have many duties and their title is unlikely to include research. They are not conducting academic research, but rapid applied work to synthesize and make available relevant data and snippets from publications that answer very local questions in an outcome-oriented way. This is published informally via websites, a monthly research bulletin, via publications like the Local Government Chronicle, or very occasionally as a conference paper." 


\section{Appendix 6 - Open Access Publishing and the health and social care system: summary of a strategic roundtable}

On the $1^{\text {st }}$ of October 2020, Health Education England (HEE) and the National Institute of Health Research (NIHR) hosted a virtual roundtable discussion with representatives from DHSC Arm's length bodies and other health and social care organisations to understand the opportunities and challenges for the health and social care system arising from the transition to Open Access publishing. This roundtable was facilitated by Information Power Ltd.

Roundtable participants voted on a selection of interventions frequently mentioned in interviews and focus groups with researchers, research managers, and library and information professionals, held by Information Power on behalf of HEE and NIHR. The following emerged as priorities, in order:

1. A shared policy and strategy

2. Shared platforms and repositories

3. Education and training

4. Increased funding

5. Cost neutral agreements with publishers

6. Tracking compliance with OA policies

In the discussion that followed, these and other priorities were explored further:

\section{Shared policy and strategy}

Participants agreed that having a common policy and high-level principles would help individual organisations focus their efforts effectively and support a shared, strategic approach to funding and negotiation with publishers. There was a strong preference for policies driving immediate open access. There are complexities to address but these should not get in the way of moving this along. Some ALBs have already signed up to a Concordat on Maximising Digital Knowledge Resources; an OA-specific policy and strategy could follow.

\section{Shared platforms and repositories}

An increasing number of NHS organisations have institutional repositories, but moving to fewer, shared platforms could avoid duplication of effort and cost and help ensure the contents are more readily discoverable. It is important that 'near research' (practitioner research) is discoverable, as well as scholarly research. It would be important not to reinvent wheels. HEE is exploring a shared NHS repository service with the British Library, and NIHR is one of the funders of Europe PMC open science platform.

\section{Education and training}

It was agreed that it was important that researchers have clear and consistent guidance about publishing their research outputs via open access routes. There needs to be improved understanding and awareness of Creative Commons Licences and the Open Government Licence.

\section{Funding}

Several points emerged in discussion. Due to austerity, publishing research in social care is now a luxury, and local authorities are more likely to be users not contributors of scholarly research. Total

45 |Recommendations about publishing and publication

procurement practices across the health and social care system.

An independent report by Information Power. 
spend on journal subscriptions across the NHS appears to be similar that of one medium-sized university. Collection and analysis of data about publishing is vital to inform decision-making but does incur costs and needs to be sustainable.

\section{Negotiation with publishers}

There was enthusiasm for central negotiation with publishers at national level. The health and care system needs to operate as an 'intelligent customer' in relation to reading and publishing research.

\section{Compliance tracking}

The benefits of including clear OA requirements in the terms and conditions of their funding agreements and active compliance tracking were discussed, along with possible sanctions for noncompliance. It was noted that in Higher Education, the provision of block grants to institutions has driven compliance both by providing funding for OA publishing fees and also by making institutional leaders aware of - and accountable for - driving forward OA. It was suggested that ALB research strategies and performance monitoring approaches could evolve to incorporate $O A$ and help drive behavioural change.

\section{From research to actionable knowledge}

It was noted that the proposed joint open access policy and strategy should also emphasise the importance of 'actionable knowledge' which can be applied in practice and inform decisions.

"OA is essential but not enough. We also need to focus on enabling research utilisation."

Related to this, there was agreement that that 'plain English' summaries are important for busy practitioners as well as members of the public. The work of the NIHR Centre for Engagement and Dissemination in producing and disseminating accessible, audience-targeted evidence summaries was highlighted.

\section{Ongoing collaboration and knowledge sharing}

Participants welcomed the suggestion that this discussion group continues to share learning. Keeping this group connected would support collective action and there are others that could be invited to join the conversation. 